\title{
Isolate-Specific Responses of the Nonhost Grass Brachypodium distachyon to the Fungal Pathogen Zymoseptoria tritici Compared with Wheat
}

\author{
Aisling Reilly, ${ }^{1}$ Sujit Jung Karki, ${ }_{1}^{1}$ Anthony Twamley, ${ }^{1}$ Anna M. M. Tiley, ${ }^{1}$ Steven Kildea, ${ }^{2}$ and Angela Feechan ${ }^{1, \dagger}$ \\ ${ }^{1}$ School of Agriculture and Food Science and UCD Earth Institute, University College Dublin, Belfield, Dublin 4, Ireland \\ ${ }^{2}$ Department of Crop Science, Teagasc Crops Environment and Land Use Programme, Teagasc, Oak Park, County Carlow, Ireland \\ Accepted for publication 23 July 2020.
}

\begin{abstract}
Septoria tritici blotch (STB) is an important foliar disease of wheat that is caused by the fungal pathogen Zymoseptoria tritici. The grass Brachypodium distachyon has been used previously as a model system for cereal-pathogen interactions. In this study, we examined the nonhost resistance (NHR) response of $B$. distachyon to two different $Z$. tritici isolates in comparison with wheat. These isolates vary in aggressiveness on wheat cultivar Remus, displaying significant differences in disease and pycnidia coverage. Using microscopy, we found that similar isolatespecific responses were observed for hydrogen peroxide accumulation and cell death in both wheat and B. distachyon. Despite this, induction of isolate-specific patterns of defense gene expression by $Z$. tritici did differ
\end{abstract}

ABSTRACT between $B$. distachyon and wheat. Our results suggest that expression of the phenylalanine ammonia lyase $P A L$ gene may be important for NHR in $B$. distachyon, while pathogenesis-related $P R$ genes and expression of genes regulating reactive oxygen species may be important to limit disease in wheat. Future studies of the B. distachyon-Z. tritici interaction may allow identification of conserved plant immunity targets that are responsible for the isolate-specific responses observed in both plant species.

Keywords: Brachypodium distachyon, fungal, fungal pathogens, nonhost, pathogen recognition by plants, wheat, Zymoseptoria tritici
Septoria tritici blotch (STB) is caused by the ascomycete fungus Zymoseptoria tritici. This disease poses a major threat to wheat production worldwide. STB is a particular concern in countries with humid, temperate climates (Fones and Gurr 2015; Orton et al. 2017).

STB control relies on the use of resistant wheat varieties together with foliar fungicide applications. However, rapid evolution of $Z$. tritici to overcome host resistance and acquire fungicide tolerance is a challenge to control this disease (Cools and Fraaije 2013; Dooley et al. 2016).

The infection cycle of $Z$. tritici includes the entry of the fungus into the host leaf, colonization of plant tissue, and formation of the asexual and sexual fruiting bodies (Steinberg 2015). Following leaf contact, the asexual pycnidiospores (conidia produced from asexual pycnidia) or sexual ascospores (produced in pseudothecia) germinate to form hyphae (Dancer et al. 1999; Palmer and Skinner 2002). Studies have shown that Z. tritici may remain epiphytic for 4 to 10 days postinoculation (dpi) and prior to infection via the stomata (Fones et al. 2017; Haueisen et al. 2019). Following infection via the stomatal openings, hyphae colonize the apoplast of the mesophyll cell layer. The infecting hyphae show no evidence of forming either haustoria or other types of specialized feeding structures (Keon et al. 2007). The wheat host remains symptomless for 7 to 10 days and this is dependent

†Corresponding author: A. Feechan; angela.feechan@ucd.ie

Funding: This project has received funding from Science Foundation Ireland (grant 15/CDA/3451) and European Union H2020 Marie Skłodowska-Curie Actions (via FP7 Marie Curie CIG grant 631269 and the Horizon 2020 Research and Innovation Programme under the Marie Skłodowska-Curie grant agreement 674964).

A. Reilly and S. J. Karki contributed equally to this work.

*The $\boldsymbol{e}$-Xtra logo stands for "electronic extra" and indicates that five supplementary figures are published online.

The author(s) declare no conflict of interest.

(C) 2021 The American Phytopathological Society on the variety. Throughout this "latent" phase, there is little or no increase in fungal biomass (Kema et al. 1996; Rudd et al. 2015). It has been suggested that the fungus may utilize internal stores of nutrition such as lipids or fatty acids at this time (Rudd et al. 2015; Steinberg 2015).

The initial recognition of pathogen attack is mediated by the plant's pattern recognition receptors that bind conserved pathogen-associated molecular patterns (PAMPs) such as fungal chitin (Miya et al. 2007; Robatzek et al. 2016). This is termed PAMP-triggered immunity (PTI). Pathogens can attempt to suppress PTI by secreting effector proteins, which in turn can be detected by plant resistance $(\mathrm{R})$ gene products. However, effectors that evade recognition can manipulate plant cellular and metabolic processes to aid pathogen infection (Boller and He 2009). For example, the LysM domain of the Z tritici effector Mg3LysM binds fungal chitin and acts to "cloak" the invading pathogen from the plant's immune system (Marshall et al. 2011; Yang et al. 2013). Following the latent phase, $Z$. tritici switches to an aggressive necrotrophic growth stage (Eyal et al. 1987; Yang et al. 2015). This is characterized by an increase in fungal biomass, degradation of the host cell wall, a collapse of mesophyll tissue cells, and the accumulation of hydrogen peroxide $\left(\mathrm{H}_{2} \mathrm{O}_{2}\right)$. The loss of cell integrity during the necrotrophic phase has been suggested to share similar characteristics to that of programmed cell death (PCD) (Yang et al. 2013). While PCD may reduce the spread of a biotrophic pathogen, it may also facilitate subsequent $Z$. tritici proliferation by providing a source of nutrition for the necrotrophic phase of growth (Keon et al. 2007). The mechanisms by which the necrotrophic phase is initiated are not entirely clear, although it has been suggested that the transition may be triggered by secreted effector proteins (Yang et al. 2015).

During the final stage of its lifecycle, $Z$. tritici produces asexual and sexual fruiting bodies inside the leaf substomatal cavity, termed pycnidia and pseudothecia, respectively. The pycnidia release asexual pycnidiospores that are dispersed to neighboring plants by rain splash (Steinberg 2015). Sexual reproduction occurs between two compatible Z. tritici stains (Mat1-1 and Mat1-2) and forms pseudothecia that appear 25 to 30 days after initial infection, 
generally, on senescent leaf tissue (Sánchez-Vallet et al. 2015; Slimane et al. 2012). These pseudothecia produce sexual ascospores dispersed by wind (Eyal et al. 1987).

Brachypodium distachyon is a grass species related to cereals in the Pooideae. B. distachyon has previously been explored as a model system for cereal-pathogen interactions, including for the study of STB (O'Driscoll et al. 2015; Omidvar et al. 2018). Here we compared the responses of $B$. distachyon (nonhost) and wheat (host) following challenge with two different $Z$. tritici isolates, IPO323 (Kema and van Silfhout 1997) and 560.11 (Lynch et al. 2016), using microscopy and gene expression studies. A better understanding of NHR in $B$. distachyon against STB may provide insights into $Z$. tritici isolate aggressiveness and the future identification of plant immunity targets.

\section{MATERIALS AND METHODS}

Plant and fungal material. Seeds of wheat (Triticum aestivum 'Remus') were kindly supplied by Prof. F. Doohan and seeds of B. distachyon (Bd21) were provided by Dr. C. Ng (School of Biology and Environmental Science, University College Dublin, Dublin, Ireland) (O’Driscoll et al. 2015; Stępień et al. 2004). Seeds of wild-type $B$. distachyon ( $\mathrm{Bd} 21)$ and the German spring wheat cultivar Remus were stratified at $4^{\circ} \mathrm{C}$ for 3 days and then incubated in the dark at room temperature for 4 days to allow germination. Germinated seeds were transferred to pots containing one-part vermiculite and three-parts peat soil. The pots were then placed in a growth chamber under a $16-\mathrm{h} / 8$-h light/dark cycle at $24^{\circ} \mathrm{C} / 12^{\circ} \mathrm{C}$ and watered every 2 days.

Z. tritici isolates IPO323 (Kema and van Silfhout 1997) and 560.11 (Lynch et al. 2016) were used for this study. Isolate 560.11 was isolated in Ireland in 2011 (Lynch et al. 2016) and isolate IPO323 was isolated in the Netherlands in 1981 (Kema and van Silfhout 1997). Prior to use, each isolate was cultured on potato dextrose agar (PDA) and grown at $20^{\circ} \mathrm{C}$ under white light supplemented with blue/black ultraviolet (UV-A) light under a 12-h/12-h light/dark cycle for approximately 7 days (O'Driscoll et al. 2015). Z. tritici cultures were grown under UV light to induce asexual sporulation in vitro (Cooke and Jones 1970; Holmes and Colhoun 1971; Kema and Annone 1991; Skinner 2001; Tiley et al. 2018; Zelikovitch and Eyal 1989). Fungal spores from PDA cultures were harvested using deionized water and the spore concentration was adjusted to $1 \times 10^{6}$ spores $/ \mathrm{ml}$ in water containing $0.02 \%$ Tween-20 solution. Each plant was sprayed with $5 \mathrm{ml}$ of spore suspension using hand-held mist spray bottles. Control plants were sprayed with $5 \mathrm{ml}$ of $0.02 \%$ Tween-20 solution each. Inoculated plants were then covered with polythene bags for $48 \mathrm{~h}$ to ensure high humidity.

Microscopic analysis. For analysis of $\mathrm{H}_{2} \mathrm{O}_{2}$ accumulation, 3,3'-diaminobenzidine (DAB) staining was performed according to Thordal-Christensen et al. (1997). Leaf sections were placed in DAB $(1 \mathrm{mg} / \mathrm{ml}), \mathrm{pH} 3.8$, for $4 \mathrm{~h}$ in the dark. Leaf samples from Z. tritici-challenged, 14-day-old wheat and Brachypodium seedlings were placed in $90 \%$ ethanol with heat for 10 min to remove chlorophyll. Dead cells and fungal structures were stained using trypan blue according to Koch and Slusarenko (1990) with a minor modification. Briefly, leaf sections were incubated in lactophenol with trypan blue $(10 \mathrm{ml}$ of lactic acid, $10 \mathrm{ml}$ of glycerol, $10 \mathrm{ml}$ of phenol, $10 \mathrm{ml}$ of water, and $10 \mathrm{mg}$ of trypan blue) for 10 to $20 \mathrm{~min}$ at $95^{\circ} \mathrm{C}$. The leaves were rinsed with water three times and destained in chloral hydrate solution $(2.5 \mathrm{~g} / \mathrm{ml}$ of water) overnight. Leaf samples were mounted onto slides with $80 \%$ glycerol and examined under a light microscope (Leica DM5500B). For quantitative analysis, cells in the field of view (FoV) were examined at $40 \times$ magnification for $0,2,7,9$, and $21 \mathrm{dpi}$. An average of approximately 830 cells in Remus and 1,600 cells in B. distachyon were counted per FoV surrounding a spore for both DAB and trypan blue-stained epidermal, guard, and mesophyll cells. The FoV values for two spores per each of the two leaves $(n=4)$ were counted. This was repeated independently twice $(n=8)$ and averaged. Images were collected over four independent experiments where two leaves (each from different plants) infected with each of the two isolates (560.11 and IPO323) were examined with a light microscope (Leica DM5500B). Images were recorded with a Leica DFC310FX digital camera.

Disease and pycnidia scores. Seedlings of the Z. triticisusceptible wheat cultivar Remus and wild-type B. distachyon $(\mathrm{Bd} 21)$ were inoculated with Z tritici isolate IPO323 or 560.11. Inoculated plants were incubated under high humidity for $48 \mathrm{~h}$ and subsequently at normal humidity at $22^{\circ} \mathrm{C}$ under a $16-\mathrm{h} / 8$-h light/ dark cycle. Diseased leaves were harvested at $0,10,14,17$, and 21 dpi. The samples were boiled for $10 \mathrm{~min}$ in ethanol to remove chlorophyll and were then mounted on glass slides for scoring. High-resolution images of slides were obtained using a flatbed scanner (Epson XP-620). The coverage of necrosis or pigment browning and pycnidia was calculated using ImageJ software for the whole leaf area (Schneider et al. 2012). Two leaves, each from different plants, were used for each time point and this was repeated over three independent experiments.

For pycnidiospore counts, four 1-cm-long leaf sections each from three leaves from individual wheat and $B$. distachyon plants inoculated with $Z$. tritici or control plants were harvested at 31 dpi. Leaves were exposed to $100 \%$ humidity for $48 \mathrm{~h}$ to induce release of pycnidiospores. The leaf sections were immersed in sterile distilled water and vortexed for $15 \mathrm{~s}$. The suspension was pipetted onto a hemocytometer for assessment of spores released from pycnidia of isolate 560.11 and IPO323 on T. aestivum 'Remus' and B. distachyon. This was repeated three times independently.

B. distachyon and wheat-extract agar. Z. tritici isolates IPO323 and 560.11 were grown on Czapek Dox-V8 juice agar (46 g/ liter of Czapek Dox agar, $200 \mathrm{ml} /$ liter of V8 Original vegetable juice (Campbell's), $3 \mathrm{~g} /$ liter of calcium carbonate, and $20 \mathrm{~g} /$ liter of agar) for 5 to 7 days under white light supplemented with blue/black UVA light under 16-h/8-h light/dark cycles at $20^{\circ} \mathrm{C}$ (Kema and Annone 1991). The vegetative, yeast-like $Z$. tritici cells were used to inoculate wheat-extract agar (WEA) (37.5 g/liter of homogenized T. aestivum 'Remus' leaves of 21 -day-old seedlings in $2 \%$ agar) and B. distachyon-extract agar (BEA) (37.5 g/liter of homogenized $B$. distachyon leaves of 21 -day-old seedlings in $2 \%$ agar). The inoculated plates were wrapped in foil for $48 \mathrm{~h}$ and then incubated as above. Petri dishes were examined every 30 days for approximately 5 months using a Leica M205 C stereo microscope. Images were captured using Leica Application Suite software version 4.4.

RNA extraction and quantitative real-time PCR. For plant gene expression studies, wheat and B. distachyon leaves (14day-old seedlings) were sampled at $0.5,48,96$, and $144 \mathrm{~h}$ postinoculation (hpi) with either of the two Z. tritici isolates or following mock treatment $(0.02 \%$ Tween-20). All samples were immediately frozen in liquid nitrogen and stored at $-80^{\circ} \mathrm{C}$ until use. Total RNA was extracted from $100 \mathrm{mg}$ of plant tissue using the RNeasy Plant Mini Kit (Qiagen, The Netherlands) and subjected to on-column DNase treatment (Sigma). Quantification of total RNA was carried out using a NanoDrop ND-1000 spectrophotometer. Reverse transcription of RNA $(1 \mu \mathrm{g})$ was carried out using the Omniscript RT Kit (Qiagen) and oligo (dT) primer using the manufacturer's instructions. Defense marker genes were analyzed by real-time quantitative reverse transcription PCR (qRT-PCR) with primers for the following: pathogenesis-related $(P R)$ genes $P R 1, P R 2$, and PR3; nonexpresser of PR gene 1 (NPR1); superoxide dismutase (SOD); catalase (CAT); phenylalanine ammonia-lyase $(P A L) ;$ 12-oxophytodienoate reductase 3 (OPR3); and two reference genes, actin and glyceraldehyde 3-phosphate dehydrogenase $(G A P D H)$, in both wheat and $B$. distachyon (Table 1). qRTPCR reactions were carried out in $12.5 \mu \mathrm{l}$ including $1.25 \mu \mathrm{l}$ of a $1: 5$ (vol/vol) dilution of cDNA, $0.2 \mu \mathrm{M}$ of primers, and $1 \times$ SYBR Premix Ex Taq (Tli RNase H plus, RR420A; Takara). PCR 
conditions were as follows: one cycle of $1 \mathrm{~min}$ at $95^{\circ} \mathrm{C} ; 40$ cycles of $5 \mathrm{~s}$ at $95^{\circ} \mathrm{C}$ and $20 \mathrm{~s}$ at $60^{\circ} \mathrm{C}$; and a final cycle of $1 \mathrm{~min}$ at $95^{\circ} \mathrm{C}$, $30 \mathrm{~s}$ at $55^{\circ} \mathrm{C}$, and $30 \mathrm{~s}$ at $95^{\circ} \mathrm{C}$ for the dissociation curve. The normalized fold change was calculated for each time relative to mock using the $2^{-\Delta \Delta \mathrm{Ct}}$ method described by Livak and Schmittgen (2001) and threshold cycle $(\mathrm{Ct})$ reference = geometric mean (Ct GAPDH: Ct Tub). Two independent experiments were carried out. Each experiment included three leaves each from three plants per isolate per time point $(n=6)$. Average $\mathrm{Ct}$ and $\mathrm{SEM}$ values were calculated from six individual $\mathrm{Ct}$ values per isolate per time point.

Statistical analysis. For gene expression studies, statistical analysis was conducted using analysis of variance incorporating the Tukey significant difference test at $P \leq 0.05$ in GraphPad Prism (version 5.03 for Windows; GraphPad Software, San Diego, CA).

All other statistical analysis was performed using the R statistical package (R Core Team 2016). The proportion of disease symptoms and pycnidia per leaf area, the proportion of dead cells stained with trypan blue per FoV, and the proportion of cells showing the presence of $\mathrm{H}_{2} \mathrm{O}_{2}$ per FoV stained with DAB were analyzed using a generalized linear model with a quasi-binomial distribution (Crawley 2012). Multiple comparison tests were performed using the emmeans function of the emmeans package.

\section{RESULTS}

T. aestivum 'Remus' and B. distachyon were compared for their response to infection with an Irish isolate (560.11) and a Dutch isolate (IPO323) of Z tritici.

Pathogenicity of the $Z$. tritici 560.11 and IPO323 isolates on wheat. Disease symptoms caused by the $Z$. tritici isolate 560.11 on wheat were more severe compared with those caused by IPO323 (Fig. 1A). At $21 \mathrm{dpi}$, disease coverage on Remus was significantly $(P<0.05)$ higher on plants inoculated with isolate $560.11(74 \pm 9 \%)$ than with IPO323 (56 $\pm 10 \%)$ (Fig. 1C). Pycnidia coverage on wheat infected with isolate 560.11 was also significantly $(P<0.05)$ higher at $14 \mathrm{dpi}(23 \pm 6 \%)$ and $21 \mathrm{dpi}(74 \pm 9 \%)$ compared with infection with IPO323 at $14 \mathrm{dpi}(2 \pm 1 \%)$ and $21 \mathrm{dpi}(45 \pm 9 \%)$, respectively (Fig. 1E).

$B$. distachyon nonhost response to $Z$. tritici isolates 560.11 and IPO323. A macroscopic response was observed in
B. distachyon to infection with both of the Z. tritici isolates (Fig. 1B). Z. tritici isolates on $B$. distachyon caused the production of brown pigments (polyphenols) (Fig. 1B; Supplementary Fig. S1). Levels of pigment accumulation on $B$. distachyon plants inoculated with the 560.11 isolate were significantly $(P<0.05)$ higher at $14 \mathrm{dpi}$ $(58 \pm 9 \%)$ and $21 \mathrm{dpi}(70 \pm 5 \%)$ compared with leaves inoculated with isolate IPO323 at $14 \mathrm{dpi}(32 \pm 6 \%)$ and $21 \mathrm{dpi}(44 \pm 8 \%)$ (Fig. 1D).

Z. tritici isolate interactions with the nonhost grass B. distachyon. Infected leaves were examined microscopically to determine whether the symptoms observed on B. distachyon with $Z$. tritici isolate 560.11 were associated with any fungal colonization (Fig. 2). Z. tritici isolate 560.11 formed intracellular hyphae within the mesophyll cell layer of $B$. distachyon (Fig. $2 \mathrm{~F}$ to $\mathrm{J}$ ) comparable to that found in the wheat cultivar Remus (Fig. 2B to E). Typically, invading hyphae grow, branch, and fuse extensively in the substomatal cavities to form pycnidia, which are dark elliptical or round structures (Hilu and Bevee 1957; Shetty et al. 2003). Rarely, a few immature pycnidia-like structures were observed on B. distachyon inoculated with $Z$. tritici isolate 560.11 after 28 dpi (Fig. 2H to J), which were similar to those observed on Remus at 28 dpi (Fig. 2C to E). However, no pycnidiospores were released from the immature pycnidia in $B$. distachyon. Remus pycnidia released pycnidiospores via oozing cirrus, which were most abundant per square centimeter with isolate 560.11 (Supplementary Fig. S2).

$Z$. tritici pycnidia production on $B$. distachyon leaf extract. The ability of $Z$. tritici to produce pycnidia in $B$. distachyon was investigated further by inducing asexual sporulation in vitro on WEA and BEA. This enabled the uncoupling of the $B$. distachyon nonhost response with the ability of this grass to support Z. tritici asexual sporulation.

Previous studies have shown that asexual sporulation can be established in Z. tritici by incubating the fungus on WEA under white light supplemented with fluorescent blue/black UV-A light, but sporulation cannot be established on water agar alone (Cooke and Jones 1970; Kema and Annone 1991; Skinner 2001; Tiley et al. 2018; Zelikovitch and Eyal 1989).

Both Z. tritici isolates IPO323 and 560.11 produced hyphal knots and pycnidia on WEA and BEA (Fig. 3). By 60 dpi, both Z. tritici isolates produced white lateral hyphae that radiated across the surface of the agar, away from the point of inoculation. These

TABLE 1. Primers and references used for the analysis of transcript profiles from Zymoseptoria tritici-infected leaves

\begin{tabular}{llll}
\hline Gene $^{\mathrm{a}}$ & \multicolumn{1}{c}{ Forward primer } & \multicolumn{1}{c}{ Reverse primer } & Study \\
\hline$T a P R 1$ & CAATAACCTCGGCGTCTTCATCAC & TTATTTACTCGCTCGGTCCCTCTG & Casassola et al. (2015) \\
$T a G A P D H$ & GGCCGGGATTGCTCTGAACG & TGGTGCTGTGCATGTGACGG & Duo et al. (2011) \\
$T a-A T u b$ & ATCTCCAACTCCACCAGTGTCG & TCATCGCCCTCATCACCGTC & Sheoran et al. (2015) \\
$T a C A T$ & CCATGAGATCAAGGCCATCT & ATCTTACATGCTCGGCTTGG & Sheoran et al. (2015) \\
$T a M n S O D$ & CAGAGGGTGCTGCTTTACAA & GGTCACAAGAGGGTCCTGAT & Casassola et al. (2015) \\
$T a P A L$ & CAAGATGGTCGAGGCTTACC & CGAAGTCGATCATGAAGCAA & This study \\
$T a O P R 3$ & TCGCCCTTCATGGACTACATG & TAGAGGATGCCGTGGTCGTT & Ding et al. (2016) \\
$T a P R 3$ & CCTCCATTATCTCGCAGTCGCTC & CGCCGTAGTTGTAGACCCCTG & Ding et al. (2016) \\
$T a P R 2$ & CGCCAACGTGTACCCCTACTT & TCTCGGAAATCACCACCTTCAC & Hong et al. (2008) \\
$B d T U A 6$ & ACCAACCTTGTGCCCTATCC & GGGCACCAGTCAACAAACTG & Gill et al. (2015) \\
$B d P A L$ & ATTCAGGCTATCCTTGCTGAGG & AGGAGCTTCCTTCCAAGATGTG & Kouzai et al. (2016) \\
$B d N P R 1$ & AGCTTCAACTCGACCAGCAT & CGATCACCACATCATTGAGC & Gill et al. (2015) \\
$B d P R 2$ & CATCAACTCCATGCGGATCTAC & GGCGATGTACTTGATGTTGACC & Hong et al. (2008) \\
$B d G A D P H$ & TTGCTCTCCAGAGCGATGAC & CTCCACGACATAATCGGCAC & Mandadi and Scholthof (2012) \\
$B d P R 1$ & AGCTCTGGCATCATCAGCATCC & CGTTGTGTGGGTCCAGGAAATC & Mandadi and Scholthof (2012) \\
$B d P R 3$ & GCTCGGCTGATTGTTCAACACG & TTGCCCGACCACAAATATGCC & Mandadi and Scholthof (2012) \\
$B d O P R 3$ & ACCCATTTCTTCTCGAATGATCCC & ACACGTGCAAGTACGGAAAGAAAG & Wang et al. (2017) \\
$B d C A T$ & GACTATTTCCCGTCCAGGTTC & CCTTCTCGATCACCATCTTCTC & Glover-Cutter et al. (2014) \\
$B d M n S O D$ & GCGCAATCAAGTTCAACGG & TCACCACCACCCTCACTG & Rudd et al. (2015) \\
$Z t T U B$ & ATCTACCGCGGAAAGGTGTCCA & TGGTCACCGACACGCTTAAAGAG & \\
\hline
\end{tabular}

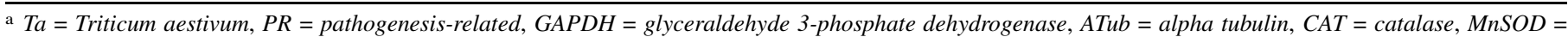
manganese-dependent superoxide dismutase, $P A L=$ phenylalanine ammonia lyase, OPR $=$ oxophytodienoate reductase, Bd $=$ Brachypodium distachyon, TUA = alpha tubulin, $N P R=$ nonexpresser of PR, Zt $=$ Zymoseptoria tritici, and TUB = beta tubulin. 
hyphae formed white hyphal knots, which are the initial stages of pycnidia development. By 5 months postinoculation, the hyphal knots had developed into dark-brown, globose pycnidia that were approximately 50 to $100 \mu \mathrm{m}$ in diameter (Fig. 3). These structures resembled pycnidia observed in planta on wheat cultivar Remus isolates, and some oozed a cirrus-like substance. Only the Z. tritici 560.11 isolate consistently formed pycnidia on BEA over two independent experiments (Fig. 3).
A

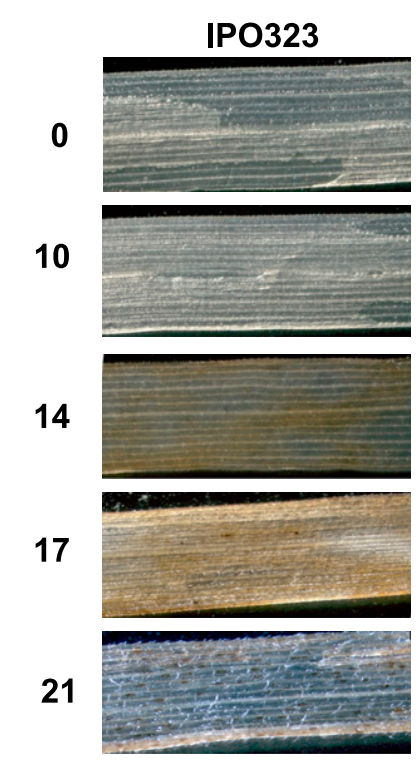

C

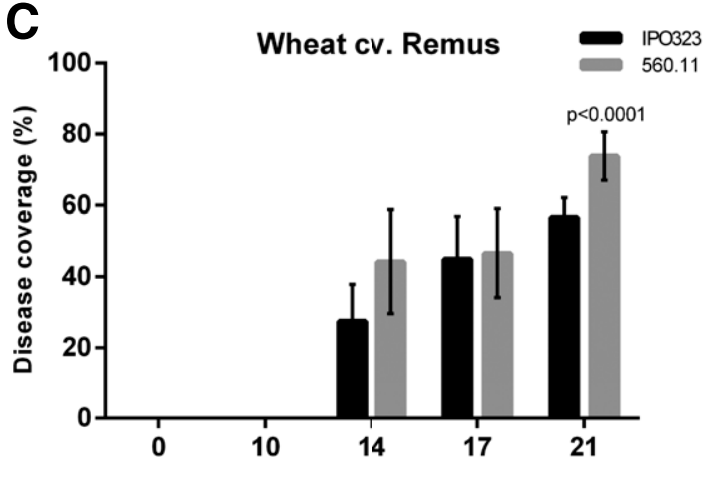

Days post inoculation

560.11
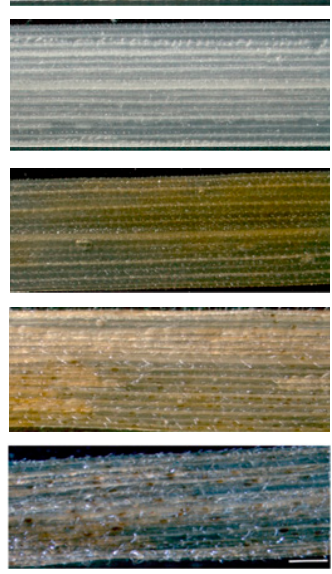

B B. distachyon (Bd-21)
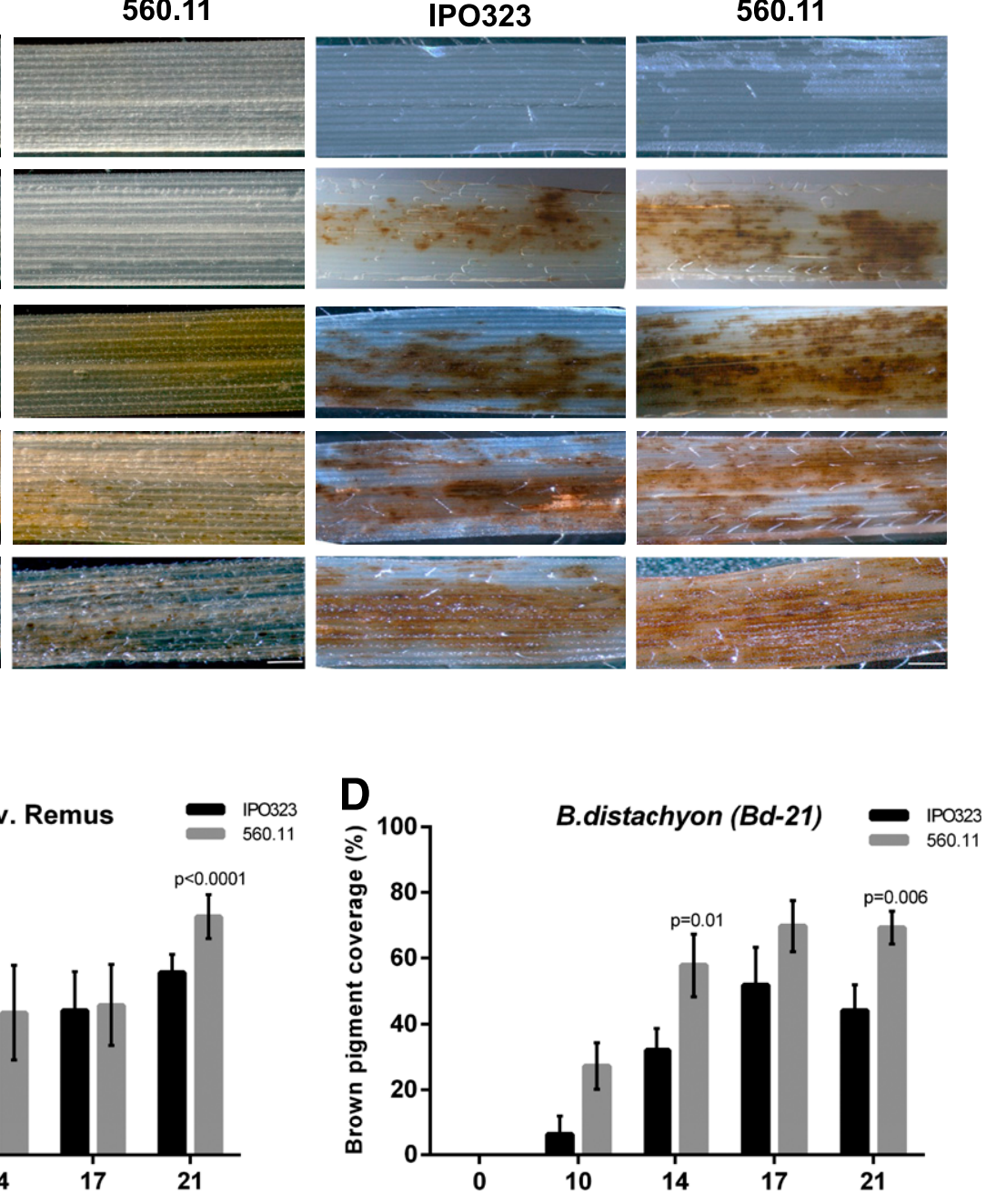

Days post inoculation

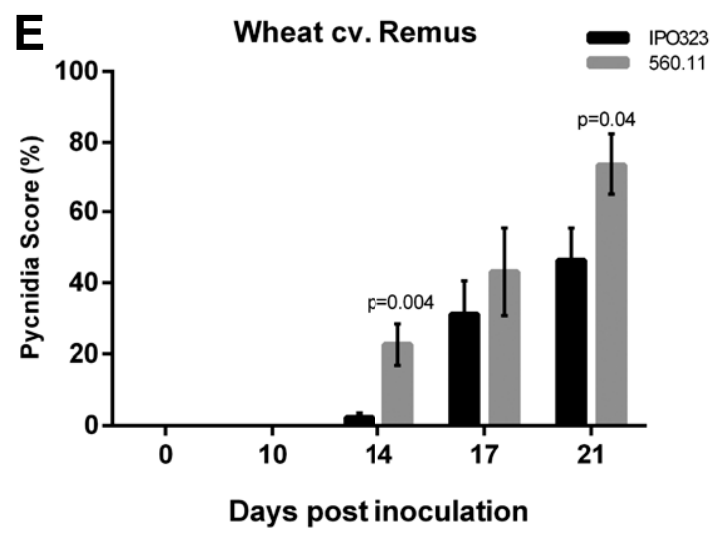

Fig. 1. Progression of symptoms on A, Triticum aestivum 'Remus' and B, Brachypodium distachyon induced by Zymoseptoria tritici isolate IPO323 and 560.11 . Infected leaves were cleared of chlorophyll by boiling in ethanol for $10 \mathrm{~min}$ and symptoms were recorded at $0,10,14,17$, and 21 days postinoculation (dpi). Two leaves each from a different plant were examined per time point. Images are representative of three independent experiments. Scale bars $=2 \mathrm{~mm}$. $\mathbf{C}$, Disease coverage on Remus and D, pigment coverage on B. distachyon at 0, 10, 14, 17, and 21 dpi. E, Pycnidia coverage on Remus. High-resolution images of diseased leaves (one per seedling of two seedlings) were obtained and coverage of symptoms and coverage of pycnidia were measured using ImageJ software. Each data point represents the mean \pm SEM of three independent experiments. $P$ values shown above bars are differences between isolates using the Tukey significant difference test at $P \leq 0.05$. 
$\mathrm{H}_{2} \mathrm{O}_{2}$ accumulation and cell death during the host wheat-Z. tritici interaction. Wheat leaves inoculated with the two Z. tritici strains were stained with DAB (Thordal-Christensen et al. 1997) and trypan blue (Koch and Slusarenko 1990) to assess $\mathrm{H}_{2} \mathrm{O}_{2}$ accumulation and cell death, respectively, at $0,2,7,9$, and 21 dpi (Figs. 4 and 5; Supplementary Figs. 3B and 4B).

Following inoculation, the cells in the FoV surrounding the site of Z. tritici spores were assessed for $\mathrm{H}_{2} \mathrm{O}_{2}$ accumulation by DAB staining. The percentage of Remus cells with $\mathrm{H}_{2} \mathrm{O}_{2}$ accumulation following infection with isolate IPO323 significantly increased between $0 \mathrm{dpi}(1 \pm 0.2 \%)$ and $2 \mathrm{dpi}(12 \pm 2 \%)$, before peaking at 9 dpi $(25 \pm 6 \%)$. A similar pattern of $\mathrm{H}_{2} \mathrm{O}_{2}$ accumulation was observed following infection with isolate 560.11; cells stained for $\mathrm{H}_{2} \mathrm{O}_{2}$ production increased to $29 \pm 6 \%$ at 2 dpi before peaking at 9 dpi $(44 \pm 7 \%)$ (Fig. 4A)

To determine responses in epidermal, guard, and mesophyll cells, these different cell types were assessed for the percentage of cells stained for $\mathrm{H}_{2} \mathrm{O}_{2}$ accumulation. No significant differences in the percentage of guard or epidermal cells accumulating $\mathrm{H}_{2} \mathrm{O}_{2}$ were found between the isolates at any of the time points. However, a significantly higher percentage of mesophyll cells was found to accumulate $\mathrm{H}_{2} \mathrm{O}_{2}$ in response to isolate $560.11(56 \pm 7 \%)$ compared with IPO323 (16 $\pm 3 \%)$ at 2 dpi. The highest percentage of $\mathrm{H}_{2} \mathrm{O}_{2}$ accumulation in wheat mesophyll cells was at 9 dpi in response to 560.11 (73 $\pm 4 \%)$, which was significantly higher than found in response to IPO323 $(32 \pm 4 \%)$ (Fig. 4B).

Following challenge with isolate IPO323, the percentage of dead cells stained by trypan blue in wheat significantly increased between 0 dpi $(0.3 \pm 0.2 \%)$ and 9 dpi $(17 \pm 5 \%)$ before leveling off. A significant increase in the percentage of dead cells was observed from 0 dpi $(0.2 \pm 0.2 \%)$ to $7 \mathrm{dpi}(5 \pm 2 \%)$ and between 9 dpi (19 \pm $6 \%)$ and $21 \mathrm{dpi}(26 \pm 5 \%)$ following challenge with isolate 560.11 (Fig. 5A).

No significant differences in the percentage of cell death in guard or epidermal cells were found when comparing between the isolates. However, a significantly higher percentage of dead mesophyll cells at 21 dpi was found in response to isolate 560.11 $(20 \pm 5 \%)$ compared with IPO323 $(7 \pm 1 \%)$ (Fig. 5B).

$\mathrm{H}_{2} \mathrm{O}_{2}$ accumulation and cell death during the $B$. distachyon nonhost-Z. tritici interaction. $B$. distachyon leaves were stained for $\mathrm{H}_{2} \mathrm{O}_{2}$ production with DAB (Thordal-Christensen et al. 1997) and for cell death using trypan blue (Koch and Slusarenko 1990) at $0,2,7,9$, and 21 dpi following challenge with isolate 560.11 and IPO323 (Figs. 4 and 5; Supplementary Figs. 3A and 4A).

Following inoculation, $B$. distachyon cells in the FoV surrounding the site of $Z$. tritici spores were assessed for $\mathrm{H}_{2} \mathrm{O}_{2}$ accumulation by DAB staining. After inoculation with isolate IPO323, the percentage of $B$. distachyon cells stained for $\mathrm{H}_{2} \mathrm{O}_{2}$ increased significantly between $0 \mathrm{dpi}(0.2 \pm 0.1 \%)$ and $7 \mathrm{dpi}(22 \pm 4 \%)$ before peaking at $9 \mathrm{dpi}(30 \pm 5 \%)$. A significant increase in the percentage of cells stained for $\mathrm{H}_{2} \mathrm{O}_{2}$ following 560.11 infection was observed earlier at 2 dpi $(28 \pm 4 \%)$ before peaking at 9 dpi $(48 \pm 5 \%)$ (Fig. 4A).

In $B$. distachyon, the percentage of epidermal cells stained for $\mathrm{H}_{2} \mathrm{O}_{2}$ accumulation in response to isolate $560.11(21 \pm 4 \%)$ was significantly higher than in response to isolate IPO323 (2 \pm $1 \%$ ) at 2 dpi (Fig. 4B). In contrast, such a significant difference was not observed in wheat (Fig. 4B). B. distachyon also had a significantly higher percentage of mesophyll cells stained for $\mathrm{H}_{2} \mathrm{O}_{2}$ accumulation in response to isolate 560.11 compared with IPO323 at 2, 7, 9 and 21 dpi. The highest percentage of DABstained mesophyll cells was observed in response to isolate 560.1 $(77 \pm 5 \%)$ at 9 dpi compared with $47 \pm 7 \%$ in response to IPO323 (Fig. 4B).

Following challenge with isolate IPO323, the percentage of cells stained with trypan blue for cell death significantly increased between 0 dpi $(0.6 \pm 0.3 \%)$ and 7 dpi $(6 \pm 2 \%)$, with a further increase not observed until $21 \mathrm{dpi}(14 \pm 4 \%)$ (Fig. 5A). Following challenge with 560.11, a significant increase in the percentage of dead cells was observed between 0 dpi $(0.5 \pm 0.3 \%)$ and 7 dpi $(14 \pm$ $5 \%$ ) before peaking at $21 \mathrm{dpi}(22 \pm 6 \%)$ (Fig. 5A).

No significant differences were observed in B. distachyon for epidermal or guard cell death with the exception of $7 \mathrm{dpi}$, in which a
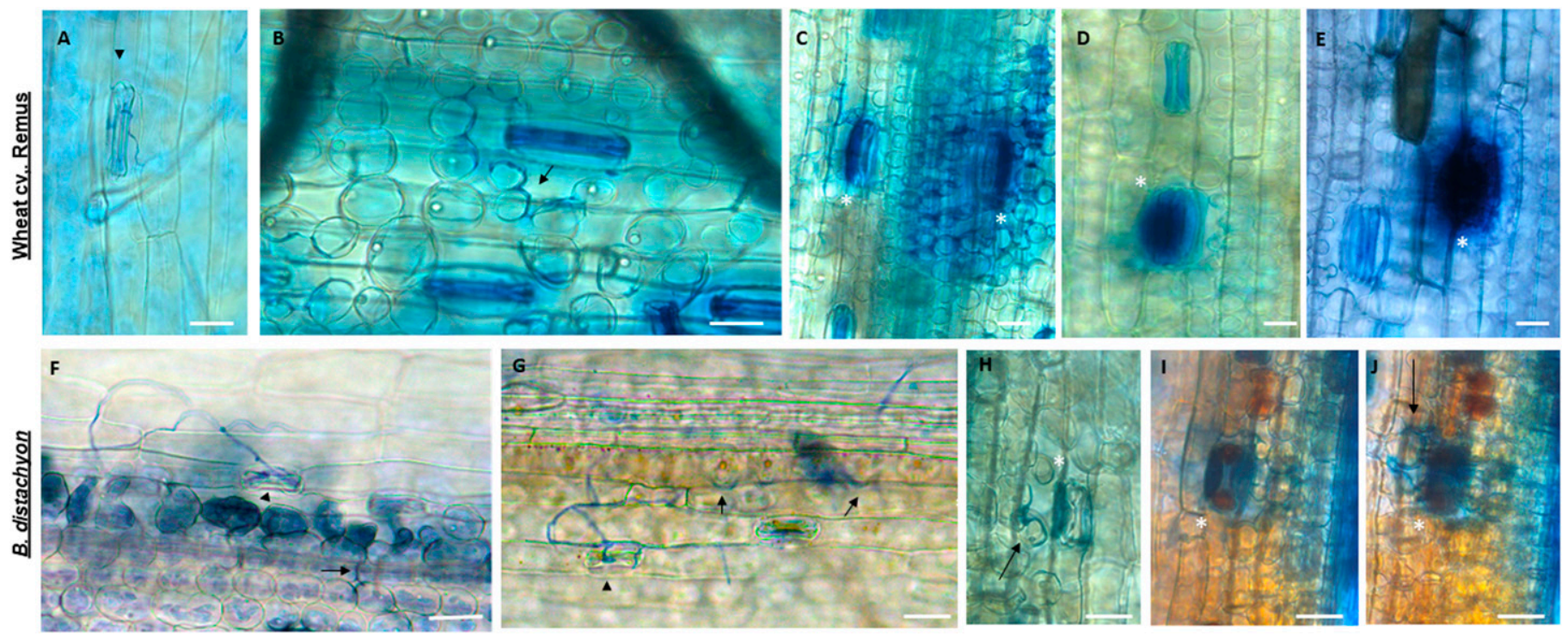

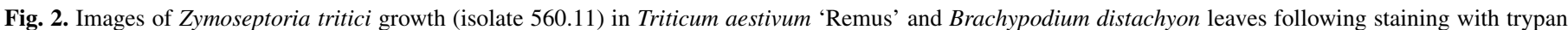

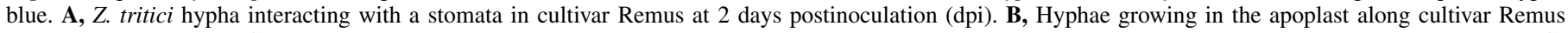

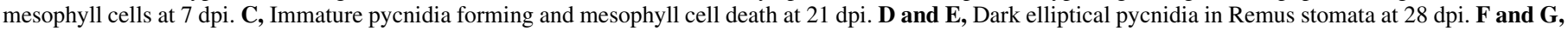

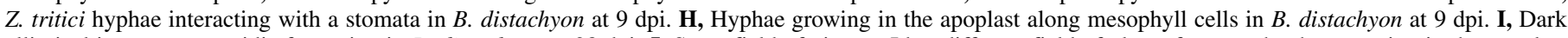

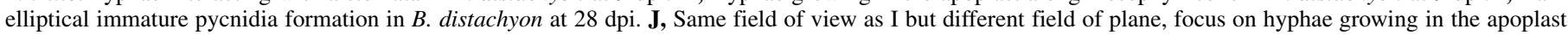

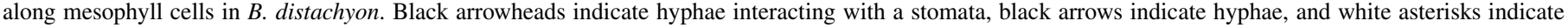
pycnidia. Scale bars $=25 \mu \mathrm{m}$. 
significantly higher percentage of dead guard cells was found in response to isolate 560.11 (41 $\pm 11 \%)$ compared with IPO323 (13 \pm 4\%) (Fig. 5B). In mesophyll cells, a significantly higher percentage of dead cells was found in response to isolate 560.11 at 9 dpi (17 \pm $4 \%)$ and $21 \mathrm{dpi}(14 \pm 2 \%)$ compared with IPO323 at 9 dpi $(3 \pm 1 \%)$ and $21 \mathrm{dpi}(7 \pm 1 \%)$ (Fig. 5B).

Defense gene expression following challenge of wheat and $B$. distachyon with the two $Z$. tritici isolates. qRT-PCR was performed to assess the induction and relative defense gene expression in wheat and $B$. distachyon during the early stages after inoculation $(0.5,48,96$, and $144 \mathrm{hpi})$ with the two different $Z$. tritici isolates.

Salicylic acid signaling pathway marker gene expression. To explore a potential role for the salicylic acid (SA) signaling pathway, the expression of $P R 1, P R 2, N P R 1$, and $P A L$ was investigated.

TaPR 1 transcripts were significantly induced in wheat inoculated with isolate IPO 323 compared with mock controls at all time points analyzed. Wheat seedlings inoculated with isolate 560.11 had significantly induced TaPRl levels only at 144 hpi. Significant differences were observed between seedlings treated with the two different isolates at $96 \mathrm{hpi}$, where TaPRl levels increased 28-fold following isolate IPO323 infection compared with a fourfold induction following 560.11 infection. Conversely, at $144 \mathrm{hpi}$, TaPR1 levels were significantly higher following isolate 560.11 infection (34-fold induction) compared with IPO323 (18-fold induction) (Fig. 6A).

Both TaPR2 and TaNPR1 transcripts were significantly higher in wheat plants infected with isolate IPO323 at $0.5 \mathrm{hpi}$ compared with those inoculated with isolate 560.11 (Fig. 6C and E). TaPR2 also had significantly higher levels following inoculation with isolate IPO323 than 560.11 at $144 \mathrm{hpi}$ (Fig. 6C).

$B d P R 1$ transcripts were only significantly induced at 144 hpi by inoculation with isolate IPO323 (Fig. 6B). No significant differences in relative transcript levels of $B d P R 2$ and $B d N P R 1$ were found in $B$. distachyon plants inoculated with either of the two Z. tritici isolates (Fig. 6D and G).

No significant induction of TaPAL in wheat was observed compared with the mock control with both isolates (Fig. 6F). However, a significant induction of $B d P A L$ was observed in $B$. distachyon relative to the mock control at 48 and 96 hpi when challenged with isolate 560.11 and was significantly different compared with induction by isolate IPO323 at 48, 96, and $144 \mathrm{hpi}$ (Fig. 6H).

Jasmonic acid signaling pathway marker gene expression. To explore the role of the jasmonic acid (JA) signaling pathway during $Z$. tritici infection, the expression of $P R 3$ and $O P R 3$ was investigated.

TaPR3 transcript accumulation was induced significantly at 0.5 , 48, and 96 hpi in wheat plants infected with isolate IPO323 compared with mock inoculation and this was significantly different to induction by 560.11 at 0.5 hpi (Fig. 7A). In $B$. distachyon plants challenged with isolate IPO323, BdPR3 transcripts were significantly induced relative to the mock control at 48 and 144 hpi. Following inoculation with the two different $Z$. tritici isolates, there was a significant difference in transcript accumulation of $B d P R 3$ at 48 and 96 hpi where isolate 560.11 induced a higher transcript level (Fig. 7B). Levels of TaOPR3 and $B d O P R 3$ transcripts were not induced following infection with either Z. tritici isolate (Fig. 7C and D).

Marker gene expression for reactive oxygen species production and turnover. To further explore the production and turnover of reactive oxygen species (ROS; $\mathrm{O}_{2}^{-}$and $\mathrm{H}_{2} \mathrm{O}_{2}$ ), the expression of $S O D$ and $C A T$ was investigated.

Significant induction of TaSOD was observed at all timepoints of wheat infected with isolate IPO323 and the transcript levels were significantly higher compared with infection with isolate 560.11
(Fig. 8A). TaCAT was significantly induced by isolate IPO323 at 48 hpi compared with the mock control and was significantly higher compared with inoculation of wheat with 560.11 (Fig. 8C). In B. distachyon, $B d S O D$ was induced relative to the control at 48 and $144 \mathrm{hpi}$, but there was no significant difference between isolate inoculations (Fig. 8B). In contrast, BdCAT was induced and differentially expressed between $B$. distachyon plants inoculated with the two different isolates. BdCAT transcript levels were significantly higher at 0.5 hpi following challenge with isolate IPO323, while 560.11 induced higher transcript levels at 48 and 96 hpi (Fig. 8D).

\section{DISCUSSION}

In previous studies, symptoms caused by $Z$. tritici on B. distachyon were found to be similar to an incompatible interaction with the wheat host. Either no stomatal penetration was observed or infection hyphae were blocked in the substomatal cavities of $B$. distachyon. In both of these cases, no intracellular infection was detected with Z. tritici isolate IPO323 (Habig et al. 2020; O'Driscoll et al. 2015). However, in this study, we found isolate-specific responses when comparing the interaction between the wheat host and the nonhost grass $B$. distachyon using the Z. tritici isolates, 560.11 (Lynch et al. 2016) and IPO323 (Kema and van Silfhout 1997). During the early stages of infection, both isolates showed an increase in biomass on $B$. distachyon, suggested by an increase in $Z t T U B$ transcripts between 0.5 and 48 hpi (Supplementary Fig. S5). Microscopic examination showed that although isolate IPO323 was unable to colonize B. distachyon, isolate 560.11 achieved stomatal penetration and intracellular growth. Furthermore, possible immature pycnidia-like formation occurred in $B$. distachyon following infection with isolate 560.11 but these were rare (Fig. 2). However, as the B. distachyon seedlings were not observed after 31 days, it is possible that these pycnidia do develop further and eventually mature. Further evidence that $B$. distachyon has the nutrients needed by $Z$. tritici to make pycnidia was supported by $Z$. tritici growth and pycnidia formation on BEA (Fig. 3). Although pycnidia-like structures were observed on $B$. distachyon, we were unable to obtain pycnidiospores from the immature pycnidia (Supplementary Fig. S2). A possibility for the

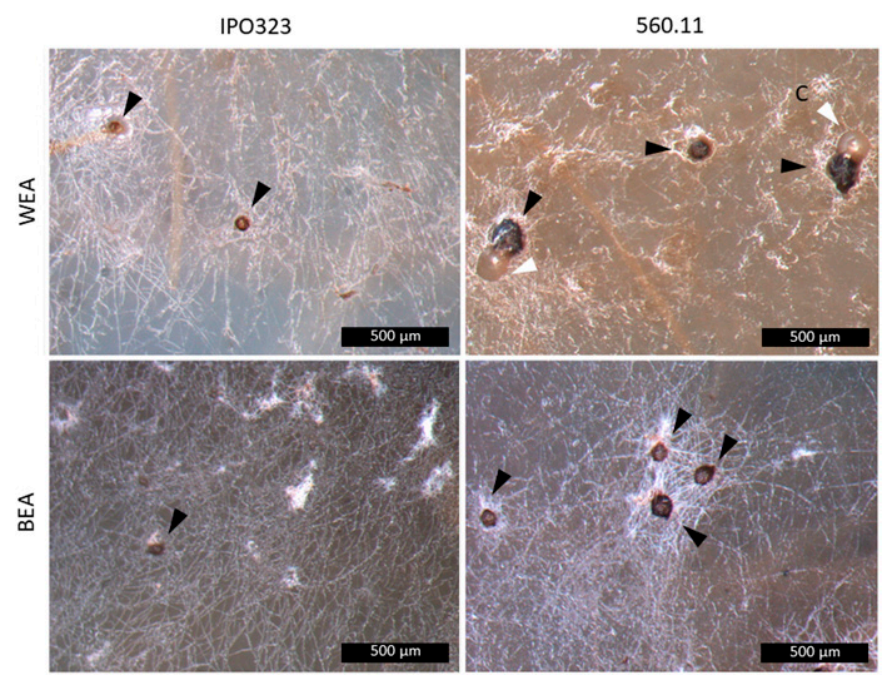

Fig. 3. Zymoseptoria tritici isolates IPO323 and 560.11 pycnidia formation on Triticum aestivum 'Remus' wheat extract agar (WEA) and Brachypodium distachyon-extract agar (BEA) at 5 months postinoculation. Isolates were incubated under white light supplemented with blue/black ultraviolet-A light on $16-\mathrm{h} / 8$-h light/dark cycles at $20^{\circ} \mathrm{C}$. Images are representative of two independent experiments and two technical repeats (plates). Black arrowheads indicate pycnidia and white arrowheads indicate cirrhus. 
lack of sporulation is that the smaller substomatal cavities in $B$. distachyon prevent mature pycnidia formation and/or pycnidiospore release, since the guard cells of $B$. distachyon are around half the size of those in wheat (Fig. 2). Immature nonsporulating pycnidia have been previously reported for $Z$. tritici infections of chlorophyll-deficient wheat leaves silenced for wheat phytoene desaturase and the magnesium chelatase subunit $\mathrm{H}$, demonstrating that pycnidia formation can be uncoupled from sporulation (Lee et al. 2015). The immature pycnidia we observed on B. distachyon were also similar to those formed by ZtVfl deletion mutants; ZtVfI

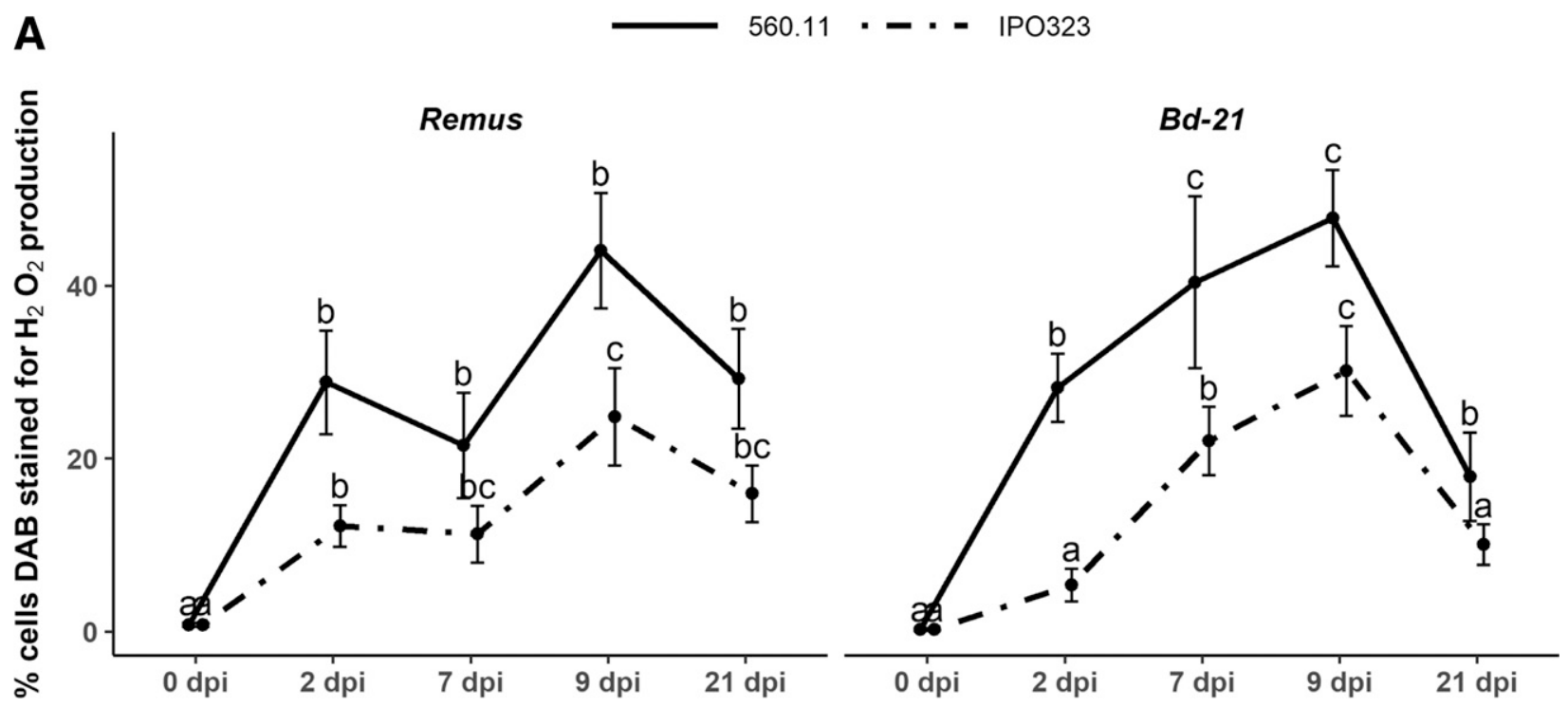

B

2 dpi

$7 \mathrm{dpi}$

9 dpi

$21 d p i$
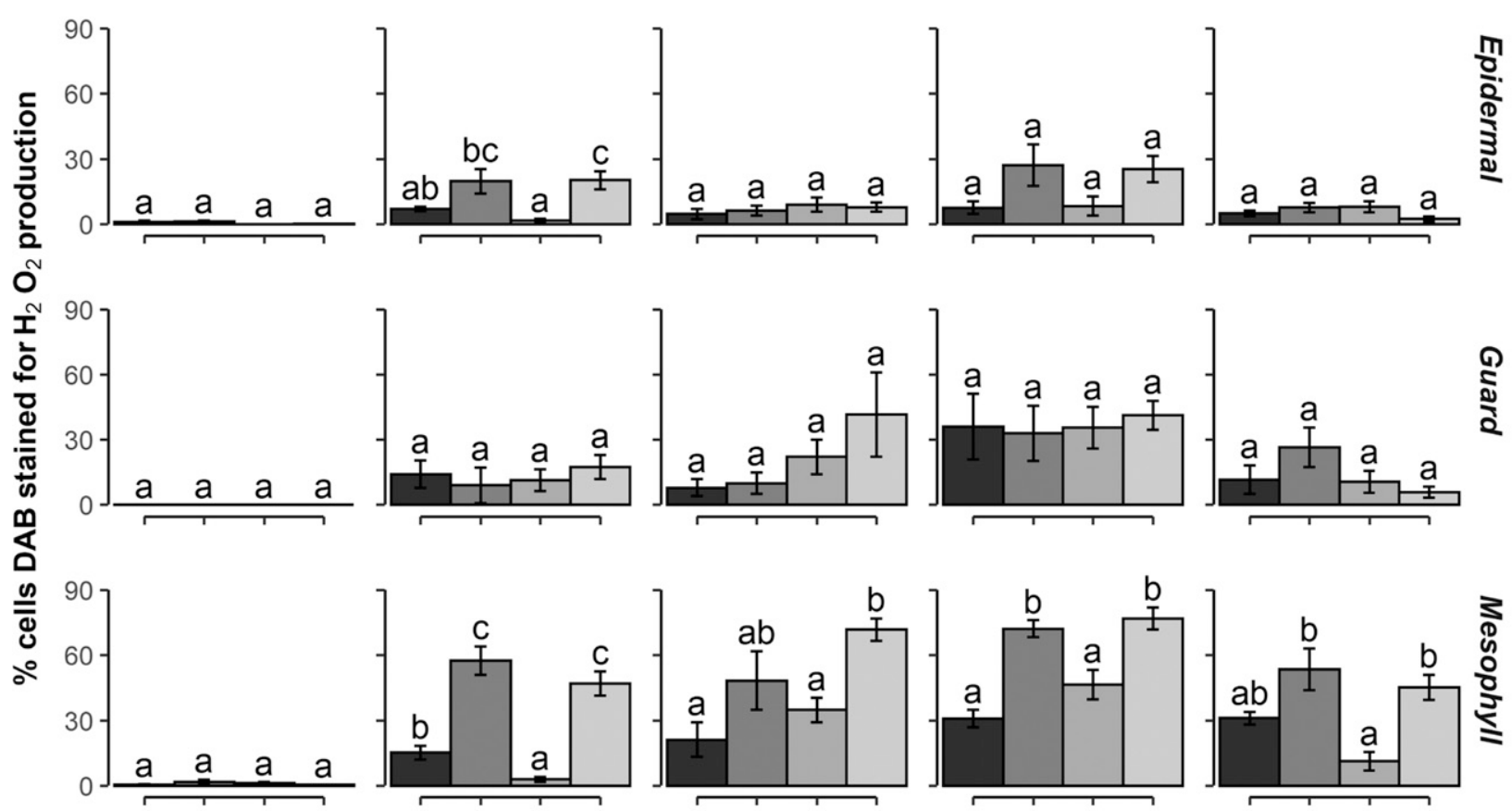

ఏ

Remus IPO323
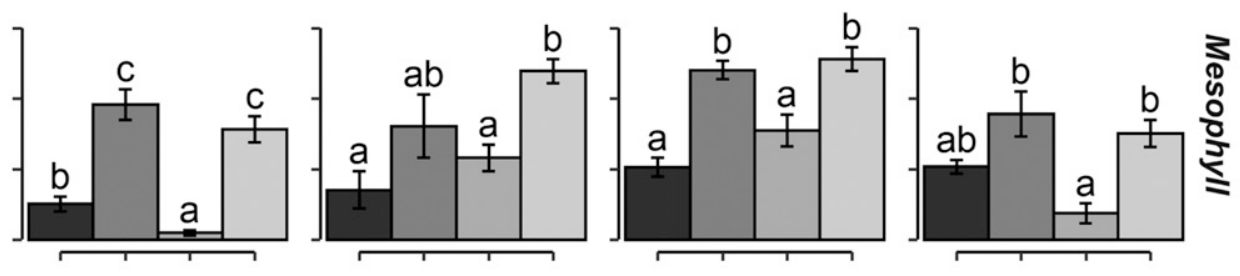

Remus 560.11

$B d-21$ IPO323

$B d-21560.11$

Fig. 4. A, Proportion of infected Triticum aestivum 'Remus' and Brachypodium distachyon cells with hydrogen peroxide $\left(\mathrm{H}_{2} \mathrm{O}_{2}\right)$ accumulation. B, Proportion of Remus and B. distachyon epidermal, guard, and mesophyll cells with $\mathrm{H}_{2} \mathrm{O}_{2}$ accumulation. Leaves infected with IPO323 and 560.11 were stained with 3,3'diaminobenzidine (DAB) at 0,2, 7, 9, and 21 days postinoculation (dpi) and mounted onto microscope slides with $80 \%$ glycerol. For each experiment, fields of view for Zymoseptoria tritici spores were examined, two per each of two leaves (independent plants). Bars represent the mean of two independent experiments $(n=$ $8)$ and error bars indicate \pm SEM. Different letters denote significant differences between Remus/B. distachyon and IPO323/560.11 at each time point $(P \leq 0.05)$ using a generalized linear model with a quasi-binomial distribution (Crawley 2012). 
encodes for a transcription factor required for full virulence of Z. tritici (Mohammadi et al. 2017).

Since isolate 560.11 was able to penetrate and intracellularly colonize $B$. distachyon, this suggests that this isolate can partially overcome the preinvasive and initial PTI responses of $B$. distachyon.
Such PTI responses are hypothesized as the means by which NHR is conferred in distantly related plants, with nonhost pathogens lacking the capabilities to overcome PTI. This may be attributable to a lack of effector targets in the nonhost or an inability of the pathogen to manipulate nonhost plant targets (Stam et al. 2014).

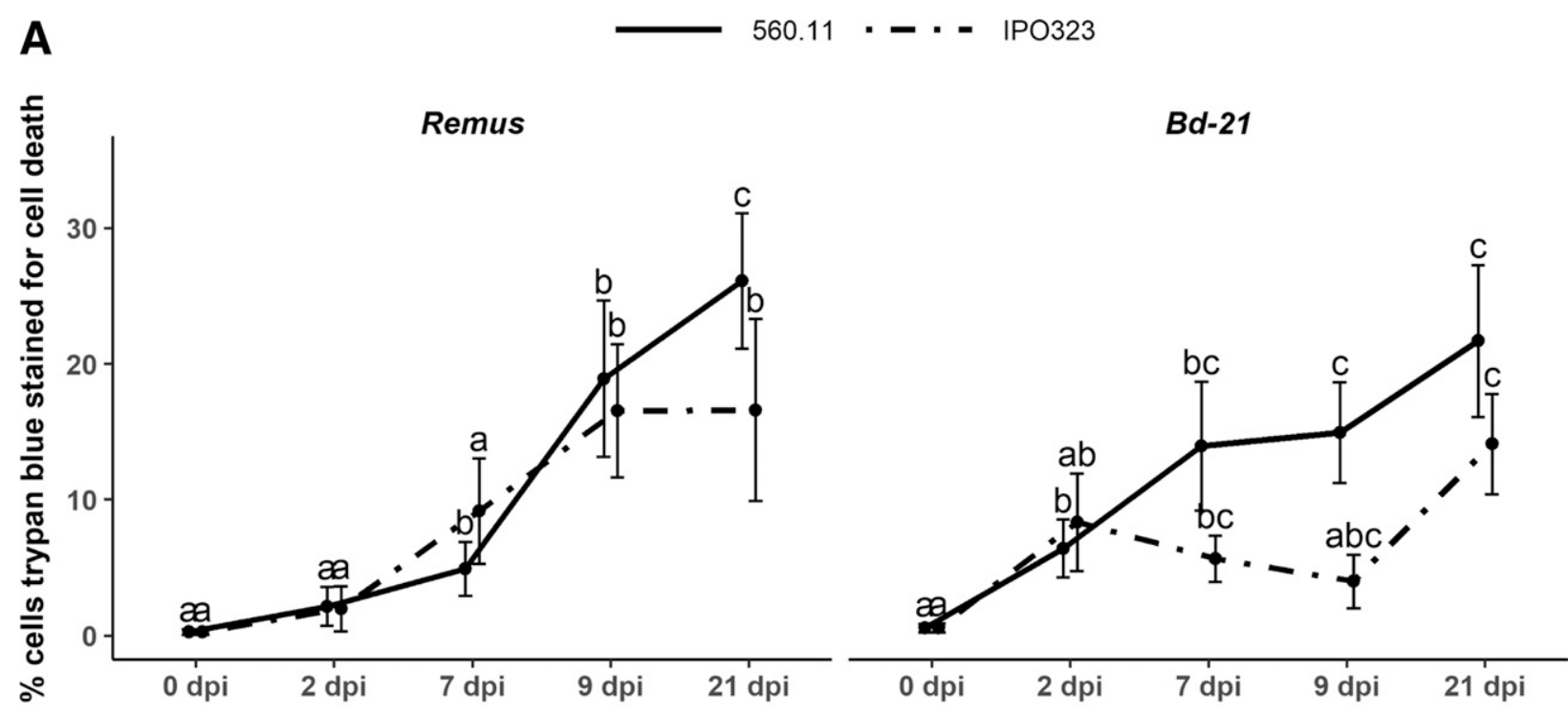

B

O dpi

$2 d p i$

7 dpi

9 dpi

21 dpi

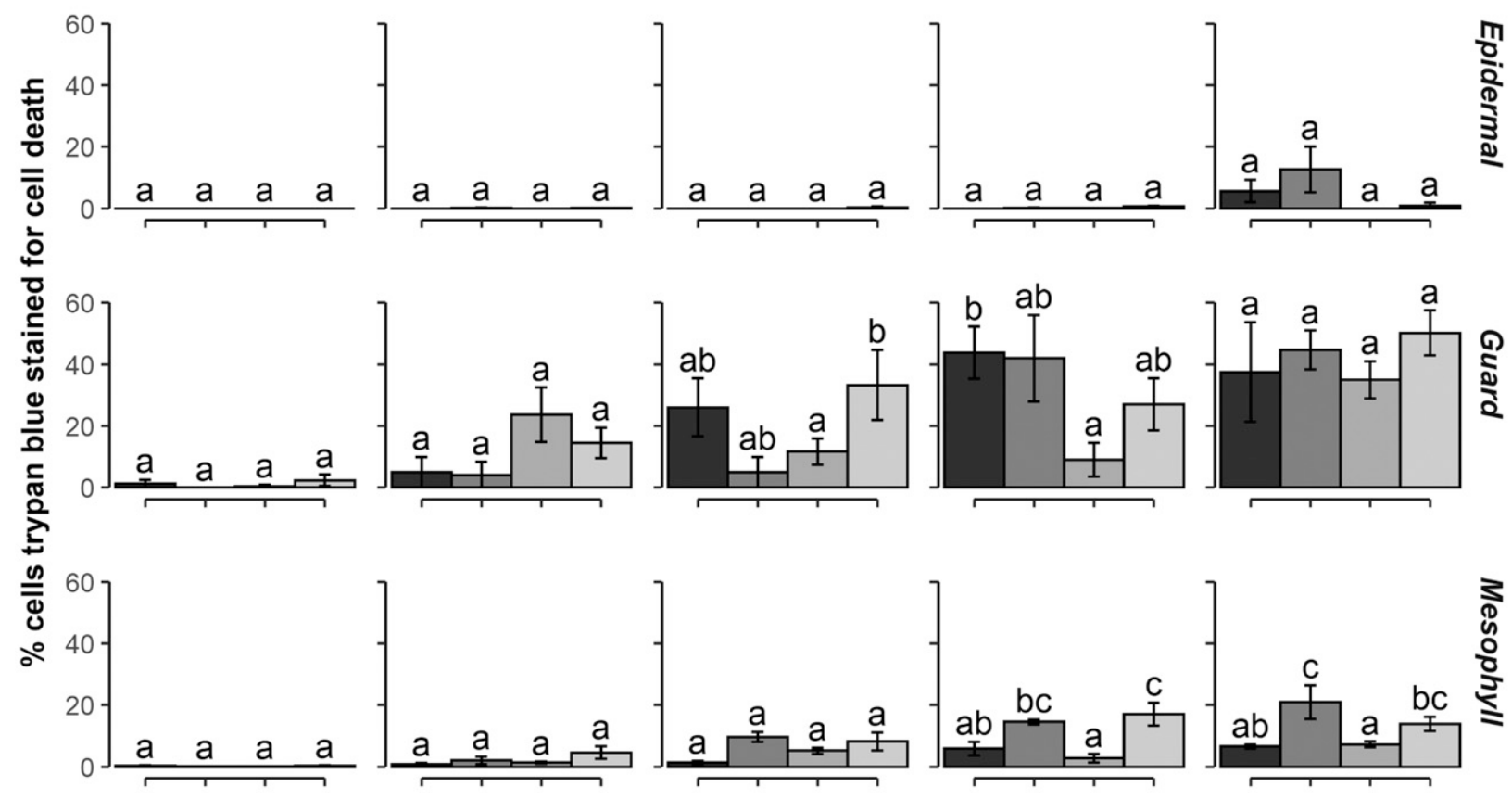

Fig. 5. A, Proportion of dead cells following infection with Triticum aestivum 'Remus' and Brachypodium distachyon. B, Proportion of Remus and B. distachyon epidermal, guard, and mesophyll dead cells. Leaves infected with IPO323 and 560.11 were stained with 3,3'-diaminobenzidine (DAB) at 2, 7, 9, and 21 days postinoculation (dpi) and mounted onto microscope slides with $80 \%$ glycerol. For each experiment, fields of view for Zymoseptoria tritici spores were examined, two per each of two leaves (independent plants). Bars represent the mean of two independent experiments $(n=8)$ and error bars indicate \pm SEM. Different letters denote significant differences between Remus/B. distachyon and IPO323/560.11 at each time point $(P \leq 0.05)$ using a generalized linear model with a quasibinomial distribution (Crawley 2012). 
There is evidence that in some cases, such responses can be manipulated depending on the effector complement in the invading pathogen. For example, RXLR effectors from Phytophthora infestans were found to suppress PTI responses in both the tomato host and the nonhost Arabidopsis (Stam et al. 2014; Zheng et al. 2014). It has been proposed that effector-triggered immunity may also contribute to NHR, since isolate-specific responses were found in both $B$. distachyon and oat (Avena sativa) to isolates of the crown rust oat pathogen Puccinia coronata f. sp. avenae (Omidvar et al. 2018). It is therefore possible that the ability of isolate 560.11 to initiate infection in $B$. distachyon results from the ability of effectors secreted by this isolate to suppress plant immunity. Indeed, it is unlikely that isolate 560.11 is the only strain of Z. tritici with the capacity to do so, and future studies may be able to utilize the interactions of $B$. distachyon with aggressive isolates such as 560.11 to identify the effectors responsible.

ROS such as $\mathrm{H}_{2} \mathrm{O}_{2}$ are believed to play a role in both host and NHR responses to pathogen invasion (Hückelhoven and Kogel 2003; Nimchuk et al. 2003). For example, $\mathrm{H}_{2} \mathrm{O}_{2}$ accumulation at the site of $Z$. tritici penetration has been associated with resistance (Shetty et al. 2003, 2007). Despite this, significant epidermal $\mathrm{H}_{2} \mathrm{O}_{2}$ accumulation and cell death have also been reported at 13 dpi in a compatible $Z$. tritici reaction with the wheat cultivar Sevin (Shetty et al. 2003). Our results are in agreement with the accumulation of $\mathrm{H}_{2} \mathrm{O}_{2}$ promoting $Z$. tritici infection, since we observed a peak of $\mathrm{H}_{2} \mathrm{O}_{2}$ accumulation at 9 dpi in both the wheat and $B$. distachyon interaction with $Z$. tritici. In addition, the percentage of cells with $\mathrm{H}_{2} \mathrm{O}_{2}$ accumulation was higher in response to the aggressive isolate 560.11 (Fig. 4). Indeed, the $\mathrm{H}_{2} \mathrm{O}_{2}$ accumulation observed at 9 dpi correlates with the switch from the latent to necrotrophic phase (Eyal et al. 1987; Yang et al. 2015). SOD and CAT are known to break down superoxide radicals $\left(\mathrm{O}_{2-}\right)$ to $\mathrm{H}_{2} \mathrm{O}_{2}$ and to break down $\mathrm{H}_{2} \mathrm{O}_{2}$, respectively. The regulation of these enzymes plays a key role in antioxidant defense of plants against pathogens (Mai et al. 2013; Zhang et al. 2008). Although wheat SOD (TaSOD) expression was significantly lower in leaves infected with $Z$. tritici isolate 560.11 than IPO323 over the majority of time points examined, TaCAT expression was significantly lower at 48 hpi. Similarly, significantly lower expression levels of $B d C A T$ were observed at 0.5 hpi in $B$. distachyon inoculated with isolate 560.11 compared with IPO323. Therefore, a low $\mathrm{H}_{2} \mathrm{O}_{2}$ turnover by CAT early during infection by isolate 560.11 in wheat and $B$. distachyon may explain the $\mathrm{H}_{2} \mathrm{O}_{2}$ accumulation observed (Fig. 4).

Significant isolate-specific differences were found for $\mathrm{H}_{2} \mathrm{O}_{2}$ accumulation in mesophyll cells from $2 \mathrm{dpi}$ and over the majority of timepoints assessed for both wheat and B. distachyon. In addition, significantly more epidermal cells stained for $\mathrm{H}_{2} \mathrm{O}_{2}$ were found in $B$. distachyon at 2 dpi following challenge with isolate 560.11 . Together our data suggest that $\mathrm{H}_{2} \mathrm{O}_{2}$ accumulation in cells associated with $Z$. tritici occurs as early as 2 dpi in both a compatible host and nonhost response, and that this is promoted by aggressive isolates. Since the level of $\mathrm{H}_{2} \mathrm{O}_{2}$ accumulation in cells is related to the isolate, it may suggest recognition via PTI or the manipulation of PTI conserved between both wheat and B. distachyon.

Cell death caused by the accumulation of ROS may trigger the switch to the necrotrophic phase of the $Z$. tritici life cycle, providing nutrients and energy for the fungus to sporulate; conversely, early cell death may limit pycnidia formation (Lee et al. 2015; Shetty et al. 2003). Previous observations during an incompatible interaction in the resistant cultivar Stakado did not show cell death until 15 dpi (Shetty et al. 2003). In our study, we recorded significant increases in cell death from 2 dpi in the nonhost grass $B$. distachyon and from $7 \mathrm{dpi}$ in the wheat host (predominantly in guard cells) (Fig. 5). It is conceivable that such early cell death in guard cells could arrest stomatal penetration and further studies
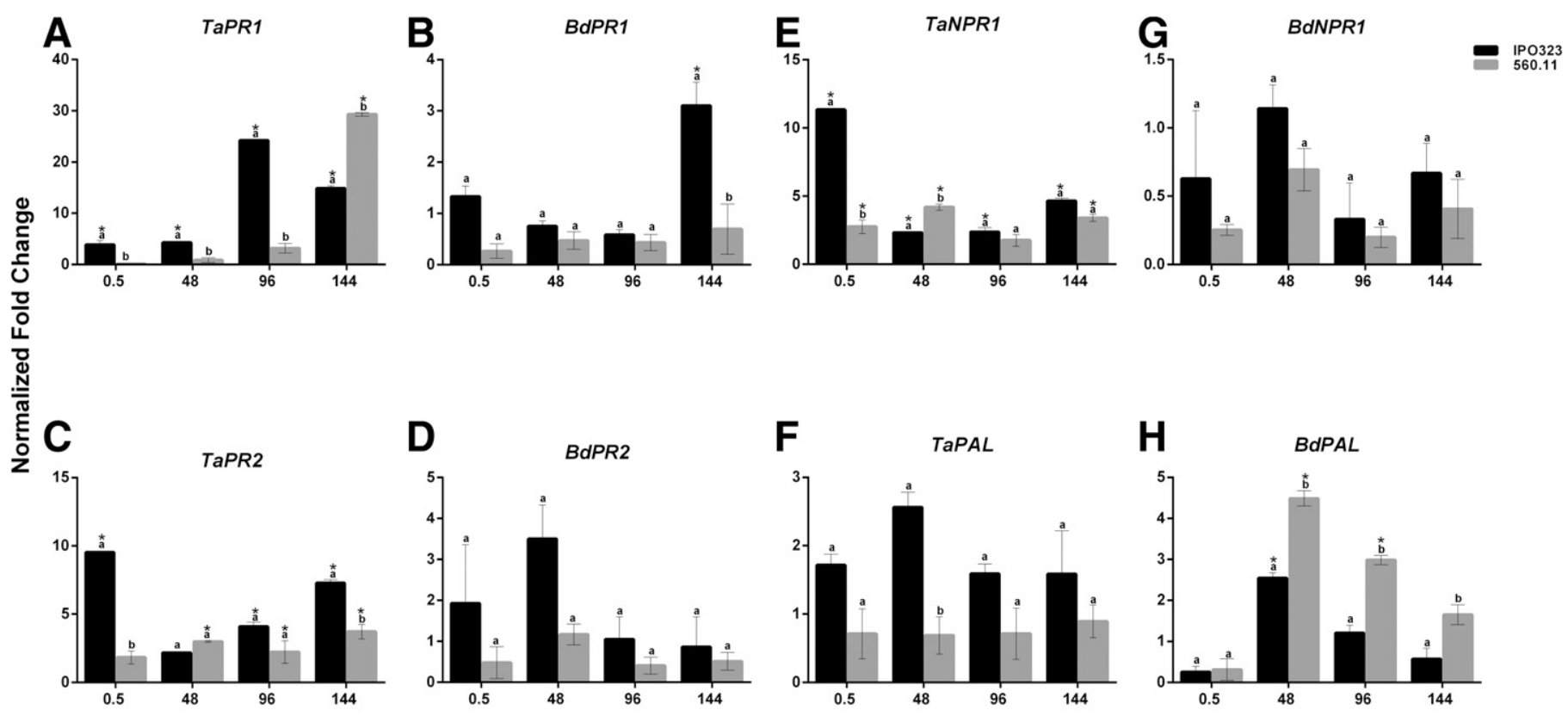

\section{hours post inoculation (hpi)}

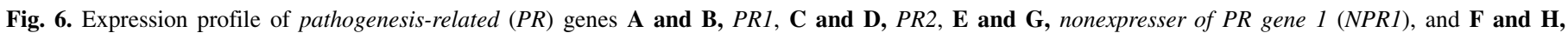

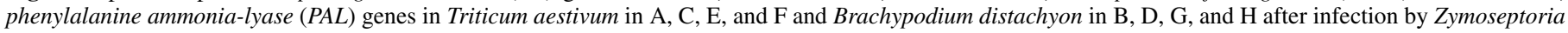

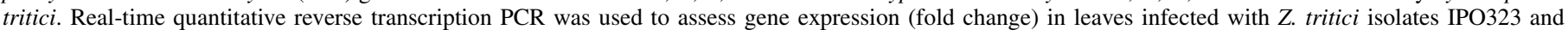

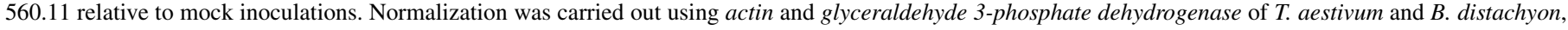

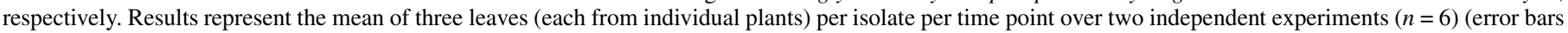

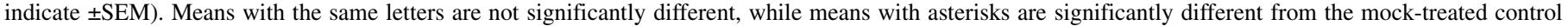
determined using the Tukey test at $P \leq 0.05$. 
could elucidate the effects of guard cell death on attempted $Z$. tritici entry. Only at $21 \mathrm{dpi}$ were isolate-specific differences in cell death observed on wheat, where cell death was higher following infection with isolate 560.11 (Figs. 1 and 5). The similar levels of cell death at earlier time points in wheat is unexpected, given that pycnidia formation was higher for isolate 560.11 at $14 \mathrm{dpi}$ as well as $21 \mathrm{dpi}$ (Fig. 1). Nonetheless, a previous study found that necrosis and pycnidia formation are largely independent (Karisto et al. 2018).

Polymerization of phenylpropanoid by peroxidase in the presence of $\mathrm{H}_{2} \mathrm{O}_{2}$ may form a chemical and/or physical barrier to Z. tritici (Barceló 1997; Ors et al. 2017). PAL catalyses the production of cinnamic acid from phenylalanine, which can be converted into phenolic compounds and lignin precursors. These compounds are in turn oxidized and polymerized into brown pigments (polyphenols) (Ngadze et al. 2012). Both Z. tritici isolates caused the production of such brown pigments (polyphenols) on B. distachyon. Despite the accumulation of brown pigmentation following infection with both $Z$. tritici isolates, browning was significantly higher for isolate 560.11 (Fig. 1B; Supplementary Fig. $\mathrm{S} 1$ ). This is consistent with the higher transcript levels of $B d P A L$ (48 to 144 hpi) found in $B$. distachyon infected with isolate 560.11 (Fig. $6 \mathrm{H})$. We found no induction of TaPAL by either $Z$. tritici isolate in the susceptible wheat cultivar Remus (Fig. 6F). However, expression of wheat TaPAL was previously reported to be induced by $Z$. tritici and was higher in the STB semi-resistant wheat cultivar Premio compared with the susceptible cultivar Alixan (Ors et al. 2017).

Higher induction of $P R$ genes against $Z$. tritici has been observed in resistant wheat cultivars, whereas little induction of these genes was observed in susceptible cultivars at initial stages of infection (Adhikari et al. 2007; Ray et al. 2003; Shetty et al. 2003). We observed that TaPR1,TaPR2, and TaNPRl were induced in wheat following $Z$. tritici infection and this was earlier and transcript levels were higher with the less aggressive isolate IPO323 (Fig. 6A, $\mathrm{C}$, and $\mathrm{E}$ ). This suggests that SA-mediated signaling is triggered in wheat possibly as a defense response against $Z$. tritici. In previous research, higher expression of $P R I$ was observed in the resistant wheat cultivar Atigo compared with the susceptible cultivar Alixan (Ors et al. 2017).

The role of plant hormones in defense against pathogen infection has been well characterized (Bari and Jones 2009; Pieterse et al. 2009) but remains unclear with respect to STB. The JA signaling pathway mediates defense against necrotrophic and hemibiotrophic pathogens ( $\mathrm{Li}$ and Yen 2008). We observed no differential expression of TaPR3 and TaOPR3 between the isolates on infected
A

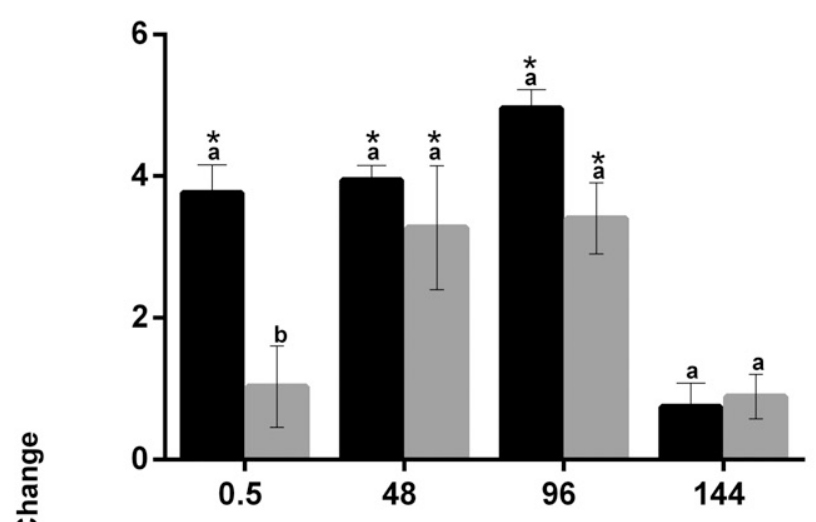

C

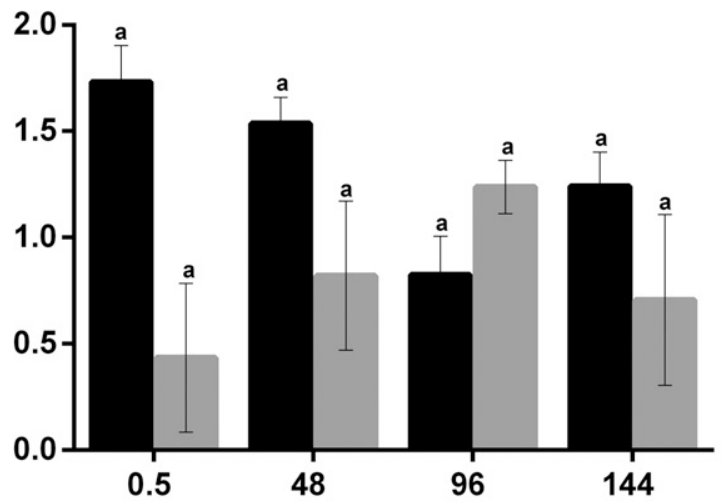

B

$B d P R 3$

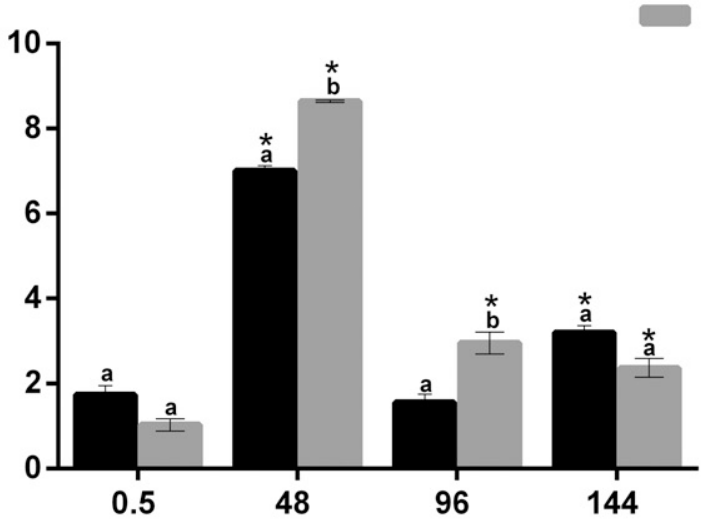

D

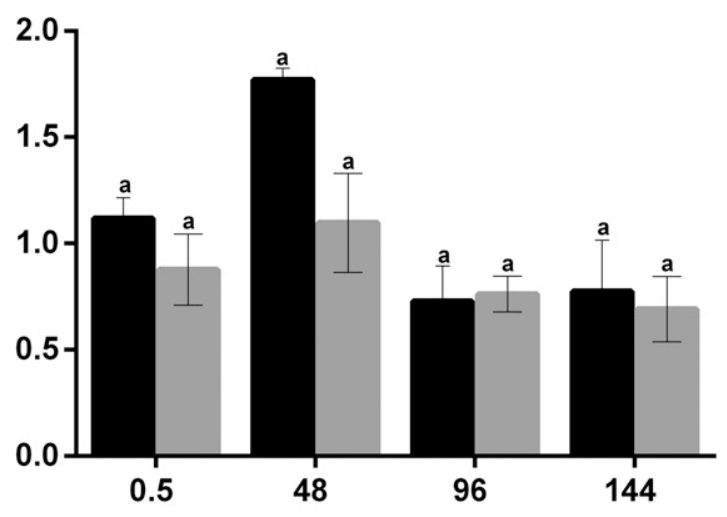

hours post inoculation (hpi)

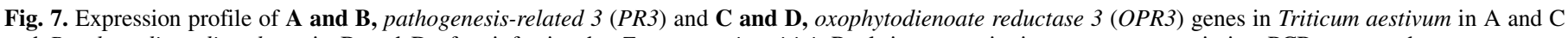

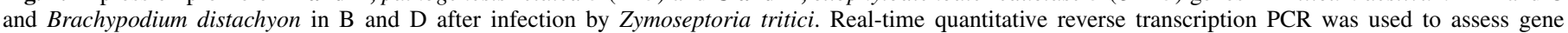

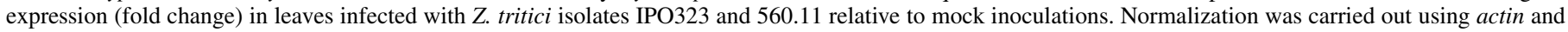

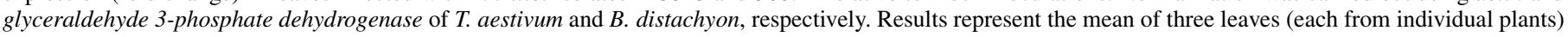

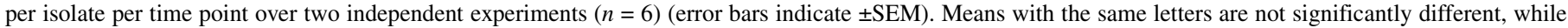
means with asterisks are significantly different from the mock-treated control determined using the Tukey test at $P \leq 0.05$. 


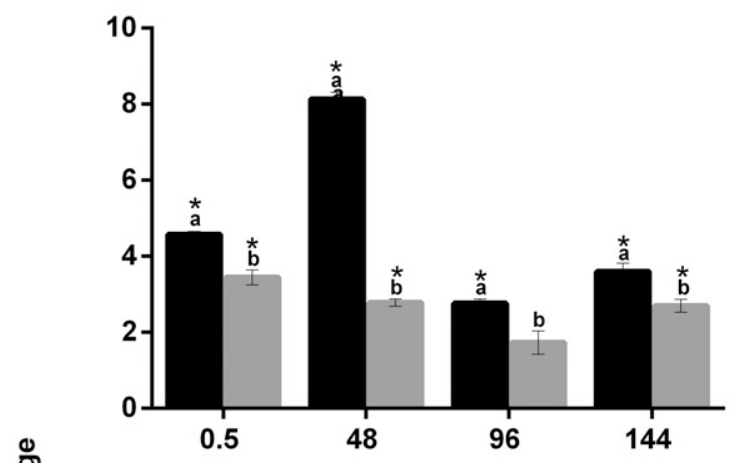

C

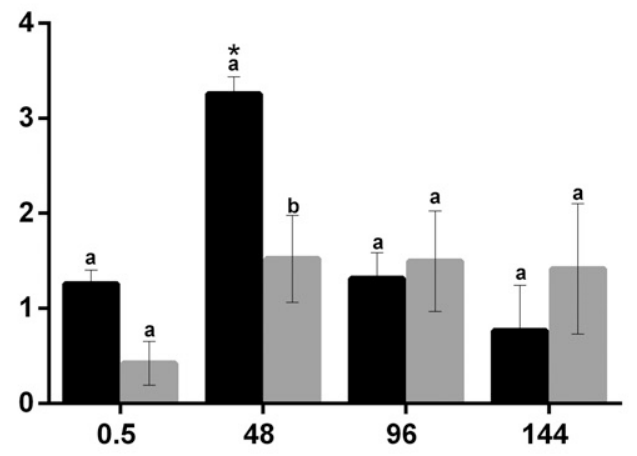

B

BdSOD1

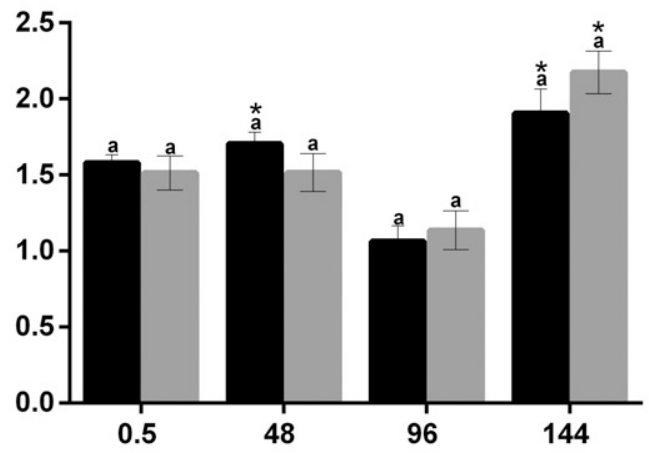

\section{hours post inoculation (hpi)}

Fig. 8. Expression of $\mathbf{A}$ and $\mathbf{B}$, superoxide dismutase (SOD) and $\mathbf{C}$ and $\mathbf{D}$, catalase (CAT) genes in Triticum aestivum in A and $\mathbf{C}$ and Brachypodium distachyon in $\mathrm{B}$ and D after infection by Zymoseptoria tritici. Real-time quantitative reverse transcription PCR was used to assess gene expression (fold change) in leaves infected with Z. tritici isolates IPO323 and 560.11 relative to mock inoculations. Normalization was carried out using actin and glyceraldehyde 3-phosphate dehydrogenase of $T$. aestivum and B. distachyon, respectively. Results represent the mean of three leaves (each from individual plants) per isolate per time point over two independent experiments $(n=6)$ (error bars indicate \pm SEM). Means with the same letters are not significantly different, while means with asterisks are significantly different from the mock-treated control determined using the Tukey test at $P \leq 0.05$.

wheat, with the exception of TaPR3 induction by isolate IPO323 at 0.5 hpi (Fig. 7A). BdPR3 transcripts were induced in $B$. distachyon following $Z$. tritici inoculation and this was higher at 48 and 96 hpi with isolate 560.11 than IPO323 (Fig. 7B).

Taken together, the expression profiles of these defense marker genes suggest that induction of SA-mediated $P R$ genes may inhibit STB disease progression in wheat but that aggressive isolates such as 560.11 may be able to interfere with this, conceivably, and this may be effector mediated. In contrast, the phenylpropanoid pathway appears to be more important for the B. distachyon NHR response against $Z$. tritici.

In conclusion, our findings show that there are similar isolate-specific responses of both $B$. distachyon and wheat to $Z$. tritici. The growth and formation of immature pycnidia of Z. tritici isolate 560.11 in both grasses may suggest that homologous susceptibility factors are conserved between $B$. distachyon and wheat. Such plant targets may be differentially manipulated by $Z$. tritici isolates, perhaps via the use of different effector repertoires. Future transcriptomic and genomic studies of the $B$. distachyon interaction with different $Z$. tritici isolates could reveal such effectors. These findings may also provide a basis to identify the genes responsible for Z. tritici recognition in this nonhost and for isolate-specific responses shared in both grass species.

\section{ACKNOWLEDGMENTS}

We thank M. Todorovic for her excellent technical help, G. Kema for the Z. tritici isolate IPO323, C. $\mathrm{Ng}$ for the B. distachyon Bd21 seed, and F. Doohan for wheat cultivar Remus seed.

\section{LITERATURE CITED}

Adhikari, T. B., Balaji, B., Breeden, J., and Goodwin, S. B. 2007. Resistance of wheat to Mycosphaerella graminicola involves early and late peaks of gene expression. Physiol. Mol. Plant Pathol. 71:55-68.

Barceló, A. R. 1997. Lignification in plant cell walls. Int. Rev. Cytol. 176: 87-132

Bari, R., and Jones, J. D. 2009. Role of plant hormones in plant defence responses. Plant Mol. Biol. 69:473-488.

Boller, T., and He, S. Y. 2009. Innate immunity in plants: An arms race between pattern recognition receptors in plants and effectors in microbial pathogens. Science 324:742-744.

Casassola, A., Brammer, S. P., Chaves, M. S., Martinelli, J. A., Stefanato, F., and Boyd, L. A. 2015. Changes in gene expression profiles as they relate to the adult plant leaf rust resistance in the wheat cv. Toropi. Physiol. Mol. Plant Pathol. 89:49-54.

Cooke, B. M., and Jones, G. D. 1970. The effect of near-ultraviolet irradiation and agar medium on the sporulation of Septoria nodorum and S. tritici. Trans. Br. Mycol. Soc. 54:221-226, IN7-IN8.

Cools, H. J., and Fraaije, B. A. 2013. Update on mechanisms of azole resistance in Mycosphaerella graminicola and implications for future control. Pest Manag. Sci. 69:150-155. 
Crawley, M. J. 2012. The R book. Wiley, Chichester, U.K.

Dancer, J., Daniels, A., Cooley, N., and Foster, S. 1999. Septoria tritici and Stagonospora nodorum as model pathogens for fungicide discovery. Pages 316-331 in: Septoria on Cereals: A Study of Pathosystems. J. A. Lucas, P. Bowyer, and H. M. Anderson, eds. ABI Publishing, New York.

Ding, L. N., Yang, G. X., Yang, R. Y., Cao, J., and Zhou, Y. 2016. Investigating interactions of salicylic acid and jasmonic acid signaling pathways in monocots wheat. Physiol. Mol. Plant Pathol. 93:67-74.

Dooley, H., Shaw, M. W., Mehenni-Ciz, J., Spink, J., and Kildea, S. 2016. Detection of Zymoseptoria tritici SDHI-insensitive field isolates carrying the $S d h C-\mathrm{H} 152 \mathrm{R}$ and $S d h D-\mathrm{R} 47 \mathrm{~W}$ substitutions. Pest Manage. Sci. 72: 2203-2207.

Eyal, Z., Scharen, A. L., Prescott, J. M., and van Ginkel, M. 1987. The Septoria diseases of wheat: Concepts and methods of disease management, 1st ed. International Maize and Wheat Improvement Center, Mexico City, Mexico.

Fones, H., and Gurr, S. 2015. The impact of Septoria tritici blotch disease on wheat: An EU perspective. Fungal Genet. Biol. 79:3-7.

Fones, H. N., Eyles, C. J., Kay, W., Cowper, J., and Gurr, S. J. 2017. A role for random, humidity-dependent epiphytic growth prior to invasion of wheat by Zymoseptoria tritici. Fungal Genet. Biol. 106:51-60.

Gill, U. S., Lee, S., and Mysore, K. S. 2015. Host versus nonhost resistance: Distinct wars with similar arsenals. Phytopathology 105:580-587.

Glover-Cutter, K. M., Alderman, S., Dombrowski, J. E., and Martin, R. C. 2014. Enhanced oxidative stress resistance through activation of a zinc deficiency transcription factor in Brachypodium distachyon. Plant Physiol. 166:1492-1505

Guo, H., Zhang, H., Li, Y., Ren, J., Wang, X., Niu, H., and Yin, J. 2011. Identification of changes in wheat (Triticum aestivum L.) seeds proteome in response to anti-trx $s$ gene. PLoS One 6:e22255

Habig, M., Bahena-Garrido, S. M., Barkmann, F., Haueisen, J., and Stukenbrock, E. H. 2020. The transcription factor Zt107320 affects the dimorphic switch, growth and virulence of the fungal wheat pathogen Zymoseptoria tritici. Mol. Plant Pathol. 21:124-138.

Haueisen, J., Möller, M., Eschenbrenner, C. J., Grandaubert, J., Seybold, H., Adamiak, H., and Stukenbrock, E. H. 2019. Highly flexible infection programs in a specialized wheat pathogen. Ecol. Evol. 9:275-294.

Hilu, H. M., and Bevee, W. 1957. Inoculation, oversummering, and susceptpathogen relationship of Septoria tritici on Triticum species. Phytopathology 47:474-480

Holmes, S. J. I., and Colhoun, J. 1971. Infection of wheat seedlings by Septoria nodorum in relation to environmental factors. Trans. Br. Mycol. Soc. 57:493-500, IN20.

Hong, S. Y., Seo, P. J., Yang, M. S., Xiang, F., and Park, C. M. 2008. Exploring valid reference genes for gene expression studies in Brachypodium distachyon by real-time PCR. BMC Plant Biol. 8:112.

Hückelhoven, R., and Kogel, K. H. 2003. Reactive oxygen intermediates in plant-microbe interactions: Who is who in powdery mildew resistance? Planta 216:891-902.

Karisto, P., Hund, A., Yu, K., Anderegg, J., Walter, A., Mascher, F., McDonald, B. A., and Mikaberidze, A. 2018. Ranking quantitative resistance to Septoria tritici blotch in elite wheat cultivars using automated image analysis. Phytopathology 108:568-581.

Kema, G. H., and van Silfhout, C. H. 1997. Genetic variation for virulence and resistance in the wheat-Mycosphaerella graminicola pathosystem III. Comparative seedling and adult plant experiments. Phytopathology 87: 266-272.

Kema, G. H., Yu, D., Rijkenberg, F. H., Shaw, M. W., and Baayen, R. P. 1996. Histology of the pathogenesis of Mycosphaerella graminicola in wheat. Phytopathology 86:777-786.

Kema, G. H. J., and Annone, J. G. 1991. In vitro production of pycnidia by Septoria tritici. Neth. J. Plant Pathol. 97:65-72.

Keon, J., Antoniw, J., Carzaniga, R., Deller, S., Ward, J. L., Baker, J. M., Beale, M. H., Hammond-Kosack, K., and Rudd, J. J. 2007. Transcriptional adaptation of Mycosphaerella graminicola to programmed cell death (PCD) of its susceptible wheat host. Mol. Plant-Microbe Interact. 20:178-193.

Koch, E., and Slusarenko, A. 1990. Arabidopsis is susceptible to infection by a downy mildew fungus. Plant Cell 2:437-445.

Kouzai, Y., Kimura, M., Yamanaka, Y., Watanabe, M., Matsui, H., Yamamoto, M., Ichinose, Y., Toyoda, K., Onda, Y., Mochida, K., and Noutoshi, Y. 2016. Expression profiling of marker genes responsive to the defence-associated phytohormones salicylic acid, jasmonic acid and ethylene in Brachypodium distachyon. BMC Plant Biol. 16:59.

Lee, W. S., Devonshire, B. J., Hammond-Kosack, K. E., Rudd, J. J., and Kanyuka, K. 2015. Deregulation of plant cell death through disruption of chloroplast functionality affects asexual sporulation of Zymoseptoria tritici on wheat. Mol. Plant-Microbe Interact. 28:590-604.
Li, G., and Yen, Y. 2008. Jasmonate and ethylene signaling pathway may mediate Fusarium head blight resistance in wheat. Crop Sci. 48:1888-1896.

Livak, K. J., and Schmittgen, T. D. 2001. Analysis of relative gene expression data using real-time quantitative PCR and the $2^{-\Delta \Delta C T}$ method. Methods 25: 402-408.

Lynch, K. M., Zannini, E., Guo, J., Axel, C., Arendt, E. K., Kildea, S., and Coffey, A. 2016. Control of Zymoseptoria tritici cause of Septoria tritici blotch of wheat using antifungal Lactobacillus strains. J. Appl. Microbiol. 121:485-494.

Mai, V. C., Bednarski, W., Borowiak-Sobkowiak, B., Wilkaniec, B., Samardakiewicz, S., and Morkunas, I. 2013. Oxidative stress in pea seedling leaves in response to Acyrthosiphon pisum infestation. Phytochemistry 93:49-62.

Mandadi, K. K., and Scholthof, K. B. G. 2012. Characterization of a viral synergism in the monocot Brachypodium distachyon reveals distinctly altered host molecular processes associated with disease. Plant Physiol. 160: 1432-1452.

Marshall, R., Kombrink, A., Motteram, J., Loza-Reyes, E., Lucas, J., Hammond-Kosack, K. E., Thomma, B. P., and Rudd, J. J. 2011. Analysis of two in planta expressed LysM effector homologs from the fungus Mycosphaerella graminicola reveals novel functional properties and varying contributions to virulence on wheat. Plant Physiol. 156:756-769.

Miya, A., Albert, P., Shinya, T., Desaki, Y., Ichimura, K., Shirasu, K., Narusaka, Y., Kawakami, N., Kaku, H., and Shibuya, N. 2007. CERK1, a LysM receptor kinase, is essential for chitin elicitor signaling in Arabidopsis. Proc. Natl. Acad. Sci. U.S.A. 104:19613-19618.

Mohammadi, N., Mehrabi, R., Mirzadi Gohari, A., Mohammadi Goltapeh, E., Safaie, N., and Kema, G. H. J. 2017. The ZtVf1 transcription factor regulates development and virulence in the foliar wheat pathogen Zymoseptoria tritici. Fungal Genet. Biol. 109:26-35.

Ngadze, E., Icishahayo, D., Coutinho, T. A., and van der Waals, J. E. 2012. Role of polyphenol oxidase, peroxidase, phenylalanine ammonia lyase, chlorogenic acid and total soluble phenols in resistance to potatoes to soft rot. Plant Dis. 96:186-192.

Nimchuk, Z., Eulgem, T., Holt, B. F., 3rd, and Dangl, J. L. 2003. Recognition and response in the plant immune system. Annu. Rev. Genet. 37:579-609.

O'Driscoll, A., Doohan, F., and Mullins, E. 2015. Exploring the utility of Brachypodium distachyon as a model pathosystem for the wheat pathogen Zymoseptoria tritici. BMC Res. Notes 8:1-10.

Omidvar, V., Dugyala, S., Li, F., Rottschaefer, S. M., Miller, M. E., Ayliffe, M., Moscou, M. J., Kianian, S. F., and Figueroa, M. 2018. Detection of race-specific resistance against Puccinia coronata f. sp. avenae in Brachypodium species. Phytopathology 108:1443-1454.

Ors, M. E., Randoux, B., Selim, S., Siah, A., Coulcaud, G., Maumené, C., Sahmer, K., Halama, P., and Reignault, P. 2017. Cultivar-dependent partial resistance and associated defence mechanisms in wheat against Zymoseptoria tritici. Plant Pathol. 67:561-572.

Orton, E. S., Rudd, J. J., and Brown, J. K. M. 2017. Early molecular signatures of responses of wheat to Zymoseptoria tritici in compatible and incompatible interactions. Plant Pathol. 66:450-459.

Palmer, C.-L., and Skinner, W. 2002. Mycosphaerella graminicola: Latent infection, crop devastation and genomics. Mol. Plant Pathol. 3:63-70.

Pieterse, C. M., Leon-Reyes, A., Van der Ent, S., and Van Wees, S. C. 2009. Networking by small-molecule hormones in plant immunity. Nat. Chem. Biol. 5:308-316.

R Core Team. 2016. R: A language and environment for statistical computing. R Foundation for Statistical Computing, Vienna, Austria. http://www.Rproject.org/

Ray, S., Anderson, J. M., Urmeev, F. I., and Goodwin, S. B. 2003. Rapid induction of a protein disulfide isomerase and defense-related genes in wheat in response to the hemibiotrophic fungal pathogen Mycosphaerella graminicola. Plant Mol. Biol. 53:741-754.

Robatzek, S., Chinchilla, D., and Boller, T. 2016. Ligand-induced endocytosis of the pattern recognition receptor FLS2 in Arabidopsis. Genes Dev. 20: 537-542.

Rudd, J. J., Kanyuka, K., Hassani-Pak, K., Derbyshire, M., Andongabo, A., Devonshire, J., Lysenko, A., Saqi, M., Desai, N. M., Powers, S. J., and Hooper, J. 2015. Transcriptome and metabolite profiling of the infection cycle of Zymoseptoria tritici on wheat reveals a biphasic interaction with plant immunity involving differential pathogen chromosomal contributions and a variation on the hemibiotrophic lifestyle definition. Plant Physiol. 167:1158-1185

Sánchez-Vallet, A., McDonald, M. C., Solomon, P. S., and McDonald, B. A. 2015. Is Zymoseptoria tritici a hemibiotroph? Fungal Genet. Biol. 79: 29-32.

Schneider, C. A., Rasband, W. S., and Eliceiri, K. W. 2012. NIH Image to ImageJ: 25 years of image analysis. Nat. Methods 9:671-675.

Sheoran, S., Thakur, V., Narwal, S., Turan, R., Mamrutha, H. M., Singh, V., Tiwari, V., and Sharma, I. 2015. Differential activity and expression profile 
of antioxidant enzymes and physiological changes in wheat (Triticum aestivum L.) under drought. Appl. Biochem. Biotechnol. 177:1282-1298.

Shetty, N. P., Kristensen, B. K., Newman, M. A., Møller, K., Gregersen, P. L., and Jørgensen, H. J. L. 2003. Association of hydrogen peroxide with restriction of Septoria tritici in resistant wheat. Physiol. Mol. Plant Pathol. 62: 333-346.

Shetty, N. P., Mehrabi, R., Lutken, H., Haldrup, A., Kema, G. H., Collinge, D. B., and Jørgensen, H. J. L. 2007. Role of hydrogen peroxide during the interaction between the hemibiotrophic fungal pathogen Septoria tritici and wheat. New Phytol. 174:637-647.

Skinner, W. 2001. Non-pathogenic mutants of Mycosphaerella graminicola. Doctoral thesis, University of Bristol, Bristol, U.K

Slimane, R. B., Bancal, P., Suffert, F., and Bancal, M. O. 2012. Localized Septoria leaf blotch lesions in winter wheat flag leaf do not accelerate apical senescence during the necrotrophic stage. J. Plant Pathol. 94: 543-553.

Stam, R., Mantelin, S., McLellan, H., and Thilliez, G. 2014. The role of effectors in nonhost resistance to filamentous plant pathogens. Front. Plant Sci. 5:582.

Steinberg, G. 2015. Cell biology of Zymoseptoria tritici: Pathogen cell organization and wheat infection. Fungal Genet. Biol. 79:17-23.

Stępień, Ł., Chełkowski, J., Wenzel, G., and Mohler, V. 2004. Combined use of linked markers for genotyping the Pm1 locus in common wheat. Cell. Mol. Biol. Lett. 9:819-827.

Thordal-Christensen, H., Zhang, Z., Wei, Y., and Collinge, D. B. 1997. Subcellular localization of $\mathrm{H}_{2} \mathrm{O}_{2}$ in plants, $\mathrm{H}_{2} \mathrm{O}_{2}$ accumulation in papillae and hypersensitive response during barley-powdery mildew interaction. Plant J. 11:1187-1194

Tiley, A., Bailey, A., and Foster, G. 2018. Exploring the genetic regulation of asexual sporulation in Zymoseptoria tritici. Front. Microbiol. 9:1859.

Wang, B., Wang, N., Song, N., Wang, W., Wang, J., Wang, X., and Kang, Z. 2017. Overexpression of AtPAD4 in transgenic Brachypodium distachyon enhances resistance to Puccinia brachypodii. Plant Biol. 19: 868-874.

Yang, F., Li, W., Derbyshire, M., Larsen, M. R., Rudd, J. J., and Palmisano, G. 2015. Unraveling incompatibility between wheat and the fungal pathogen Zymoseptoria tritici through apoplastic proteomics. BMC Genomics 16: 362.

Yang, F., Li, W., and Jørgensen, H. J. L. 2013. Transcriptional reprogramming of wheat and the hemibiotrophic pathogen Septoria tritici during two phases of the compatible interaction. PLoS One 8:e81606.

Zelikovitch, N., and Eyal, Z. 1989. Maintenance of virulence of Septoria tritici cultures. Mycol. Res. 92:361-364.

Zhang, S. Z., Hua, B. Z., and Zhang, F. 2008. Induction of the activities of antioxidative enzymes and the levels of malondialdehyde in cucumber seedlings as a consequence of Bemisia tabaci (Hemiptera: Aleyrodidae) infestation. Arthropod-Plant Interact. 2:209-213.

Zheng, X., McLellan, H., Fraiture, M., Liu, X., Boevink, P. C., Gilroy, E. M., Chen, Y., Kandel, K., Sessa, G., Birch, P. R., and Brunner, F. 2014. Functionally redundant RXLR effectors from Phytophthora infestans act at different steps to suppress early flg22-triggered immunity. PLoS Pathog. 10: e1004057. 